\title{
Desarrollo de una metodología para la gerencia de proyectos del sector aeroespacial en Colombia*
}

| Fecha de recibido: 23 de febrero del 2021 | Fecha de aprobación: 20 de abril del 2021 |

\author{
Giovanna Estefanía \\ Ramírez-Ruiz \\ Ingeniera electrónica \\ Escuela Colombiana de Ingeniería Julio Garavito \\ Colombia \\ Unidad de Proyectos \\ Rol de investigador: teórico \\ http://orcid.org/0000-0003-1686-7381 \\ $\bowtie$ giovanna.ramirez@epfac.edu.co
}

\section{Daniel Leandro Cárdenas-Sabogal \\ Ingeniero civil}

Escuela Colombiana de Ingeniería Julio Garavito

Colombia

Unidad de Proyectos

Rol de investigador: experimental http://orcid.org/0000-0001-8976-2789

$\bowtie$ daniel.cardenas-s@mail.escuelaing.edu.co

\section{Miguel Ángel García-Molina \\ Ingeniero mecánico}

Escuela Colombiana de Ingeniería Julio Garavito Colombia

Unidad de Proyectos

Rol de investigador: experimental http://orcid.org/0000-0002-6550-6390

$\bowtie$ miguel.garcia-mo@mail.escuelaing.edu.co

* Artículo de investigación derivado del proyecto "Desarrollo de una metodología para la gerencia de proyectos del sector aeroespacial en Colombia”, realizado por Giovanna Ramírez, Daniel Cárdenas y Miguel García, bajo la supervisión de Ricardo Benavides, con el fin de facilitar la articulación en los procesos de gerencia de proyectos del sector aeroespacial en Colombia, y así proporcionar una herramienta que permita estandarizar dichos procesos.

Para citar este artículo: Ramírez-Ruiz, G. E., Cárdenas-Sabogal, D. L., \& García-Molina, M. Á. (2021). Desarrollo de una metodología para la gerencia de proyectos del sector aeroespacial en Colombia. Ciencia y Poder Aéreo, 16(1), 116-138. https://doi.org/10.18667/cienciaypoderaereo.700

dichos proses. 


\section{Desarrollo de una metodología para la gerencia de proyectos del sector aeroespacial en Colombia}

Resumen: Este artículo propone una metodología para la gerencia de proyectos del sector aeroespacial en Colombia, como herramienta de apoyo y complemento en los procesos de inicio, planeación, ejecución, monitoreo, control y cierre de los proyectos referentes al sector. Lo anterior, en vista de que actualmente cada una de las entidades realiza proyectos con procesos y actividades propios de cada entidad, lo que genera una débil articulación entre las organizaciones, las instancias y los actores del desarrollo de proyectos espaciales y, como consecuencia, se genera una baja competitividad por parte de estas organizaciones en Colombia. Dicha metodología contiene 36 procesos ajustados a las necesidades del sector, acompañados de procedimientos, diagramas de flujo y formatos a seguir durante la gerencia de proyectos. Para su desarrollo, se inició con la identificación, descripción y comparación de estándares internacionales, marcos de referencia y buenas prácticas en gerencia de proyectos, seguido de un análisis del sector aeroespacial en Colombia. Por último, la construcción de la metodología se hizo con los procesos ajustados de acuerdo con los antecedentes y su validación, en la cual, se obtuvieron resultados satisfactorios por parte de los expertos seleccionados para la validación del método.

Palabras clave: gerencia de proyectos; metodología; planeación; procesos; sector aeroespacial.

\section{Development of a Project Management Methodology for the Colombian Aerospace Sector}

Abstract: This article suggests a project management methodology for the Colombian aerospace sector that serves as a complementary support tool in the initiation, planning, execution, monitoring, control, and closure of initiatives. The foregoing, in view of the current trend by the organizations in this sector of developing individual and independent projects, a situation that generates a weak articulation between entities, instances, and actors for the development of space projects, and, as a result, low competitiveness for the national aerospace industry. The proposed methodology comprises 36 processes that were adjusted to the needs of the sector, along with a series of procedures, flow diagrams, and formats to be followed during project management. Its development involved the identification, description and comparison of international standards, reference frameworks, and good practices in project management, followed by an analysis of the Colombian aerospace sector. Finally, the construction of the methodology was performed using the adjusted processes, after analyzing their background and carrying out their validation, phase in which satisfactory results were reported by the experts in charge.

Keywords: Project management; methodology; planning; processes; aerospace sector.

\section{Desenvolvimento de uma metodologia para a gerência de projetos do setor aeroespacial na Colômbia}

Resumo: Este artigo propõe uma metodologia para a gerência de projetos do setor aeroespacial na Colômbia, como ferramenta de apoio e complemento nos processos de início, planejamento, execução, monitoramento, controle e encerramento dos projetos relativos ao sector. Tendo em conta que atualmente cada uma das entidades realiza projetos com processos e atividades próprias de cada entidade, o que gera uma fraca articulação entre as organizações, as instâncias e os atores no desenvolvimento de projetos espaciais e, consequentemente, é gerada a baixa competitividade destas organizações na Colômbia. Esta metodologia contém 36 processos adaptados às necessidades do sector, acompanhados de procedimentos, diagramas de fluxo e formatos a seguir durante a gerência de projetos. Para seu desenvolvimento, começou com a identificação, descrição e comparação de padrões internacionais, marcos de referência e boas práticas em gerência de projetos, seguido de uma análise do sector aeroespacial na Colômbia. Por último, a construção da metodologia foi feita com os processos ajustados de acordo com os antecedentes e a sua validação, na qual se obtiveram resultados satisfatórios por parte dos especialistas escolhidos para a validação do método.

Palavras-chave: gerenciamento de projetos; metodologia; planejamento; processos; setor aeroespacial. 
En el ámbito internacional, el sector aeroespacial se compone de funciones de la industria aeronáutica y espacial. La industria aeronáutica se caracteriza por su desempeño en actividades pertinentes al diseño, elaboración, distribución y mantenimiento de aeronaves y equipos específicos asociados; mientras que la industria espacial comprende las mismas actividades, pero para el caso de naves espaciales, cohetes, satélites, lanzadoras y otros sistemas relacionados (Universidad Politécnica de Madrid, 2017).

Hoy en día, de manera global la industria aeroespacial simboliza una considerable evolución de las industrias en el mundo, e igualmente, consolida un crecimiento estimado entre el 6 y $7 \%$ cada año; y se estima que en los próximos 20 años esta cifra se duplicará, lo que representa una mayor oportunidad de acceder a proyectos de alta tecnología con la proyección de "un futuro asegurado y enorme" (Delgado-Gómez, 2018, p. 3).

Debido al crecimiento del sector y el incremento de proyectos en esta área, surge la necesidad de implementar metodologías para su gerenciamiento que mejoren la articulación de los procesos utilizados en la actualidad. En ese sentido, este documento tiene cuatro objetivos: (I) identificar, describir y comparar estándares, marcos de referencia y buenas prácticas en gerencia de proyectos; (II) analizar el sector aeroespacial en Colombia en el área de gerencia de proyectos; (III) diseñar una metodología para la gerencia de proyectos del sector aeroespacial de Colombia, y (IV) validar la metodología.

De modo que, el propósito de esta investigación es facilitar la articulación en los procesos de gerencia de los proyectos de este sector y, proporcionar una herramienta que permita estandarizarlos.

\section{Justificación}

El sector aeronáutico colombiano mantiene un crecimiento anual que se evidencia, entre otros componentes, en la estructura de entidades, clústeres, asociaciones y federaciones aeroespaciales constituidas ante la exigencia de generar proyectos de la industria e internacionalmente potencializar su trascendencia. Se compone de 159 organizaciones que se esfuerzan conjuntamente en un compendio de cadena de valor, mediante cinco canales de servicio: ingeniería, fabricación, educación, suministros y mantenimiento (Granada et al., 2017).

En la actualidad, las organizaciones del sector aeroespacial en Colombia realizan proyectos según procesos de gerencia internos de cada entidad, lo que limita la articulación en el lenguaje de comunicación y la sinergia entre las entidades. De acuerdo con la Corporación de la Industria Aeronáutica Colombiana (CIAC, 2020) y la Fuerza Aérea Colombiana (FAC), no se está utilizando una guía unificada o específica para la gerencia de proyectos aeroespaciales. Además, indica Gustavo Saavedra, coronel retirado de la FAC y partícipe activo en proyectos con la CIAC, que "se están presentando proyectos con diferentes parámetros de entrega” (Comunicación personal, Saavedra, 2019). Todo lo anterior, son causa de la débil articulación entre instancias y actores del sector para el desarrollo de proyectos espaciales, que conlleva a la baja productividad y competitividad de esta industria en el país (Consejo Nacional de Política Económica y Social [Conpes], 2020).

Por una parte, ya existe una alianza para la creación de proyectos entre la CIAC y la FAC, lo que ha generado que en las dos organizaciones se unan esfuerzos para obtener mejores resultados, "juntos se pusieron al nivel de los productores de bienes y servicios aeroespaciales y adquirieron certificaciones europeas y norteamericanas de la industria aeroespacial" (Comunicación personal, Saavedra, 2019). Esta es la oportunidad para aprovechar y centralizar los procesos de gerencia internos y promover mayores oportunidades en el sector.

Cuando se habla del sector aeroespacial internacional, se hace referencia a un sector pionero en diversas áreas que se ha establecido gracias a los logros obtenidos a través de la historia. Pese a ello, en Colombia este sector tiene una mínima participación, comparado con el mercado (Granada et al., 2017). Para contribuir con el desarrollo de los procesos ya existentes, se ve la necesidad de implementar una metodología para uso específico de este sector enfocada en la 
gerencia de proyectos, que permita establecer una articulación entre las organizaciones, las instancias y los actores del área aeroespacial.

Internacionalmente el mercado aeroespacial y de defensa asciende alrededor de los 674 billones de dólares. Cerca de la mitad del mercado estadounidense concierne al $51 \%$ del valor mundial. Consecutivo a este país, se encuentran entre los cuatro mercados más importantes: Francia, Reino Unido, Alemania y Canadá, aunque en la escena mundial están creciendo países como China, Brasil, India, Singapur y México, que, armonizados, simbolizan el $7 \%$ de la industria global en ventas (Granada et al., 2017).

Según el Plan Estratégico de la Industria Colombiana (Peica), elaborado por actores de la Acopaer, en términos generales del ámbito nacional "la industria manufacturera aeroespacial es inmadura" (Comunicación personal, Saavedra, 2019), pese a que cuenta con las iniciativas de desarrollo industrial lideradas por la industria militar, principalmente por la FAC. Entonces bien, solo si existe una verdadera voluntad de alto gobierno, es probable que estas iniciativas se intensifiquen, teniendo un mercado aún por explorar: la aviación civil. Por otra parte, no hay suficiente información integrada sobre la industria colombiana disponible para las organizaciones gubernamentales, así como falta de datos cuantificados (Granada et al., 2017).

\section{Metodología de la investigación}

Para la exposición de esta investigación, se planteó atribuir una metodología basada en la investigación aplicada no experimental, debido a que el estudio fue característico de procesos teóricos y prácticos (existentes) de la gerencia moderna de proyectos, a los procesos del sector aeroespacial en Colombia.

Por consiguiente, se efectuó una investigación exploratoria para recopilar información histórica y realizar el análisis de los procesos de gerencia internos, que permitiera caracterizar el sector aeroespacial en Colombia. Además, se llevó a cabo un diagnóstico literario con especial interés en los principales estándares de gerencia de proyectos que pueden aplicarse a las entidades del sector aeroespacial nacional $\mathrm{y}$, posteriormente, tenerlos en cuenta en el análisis de la metodología propuesta (Bello, 2017).

De acuerdo con la breve descripción realizada, la investigación está compuesta por cuatro fases.

\section{Fase 1. Identificar, describir y comparar estándares, marcos de referencia y metodologías en gerencia de proyectos}

Como se mencionó, esta fase busca identificar, analizar, describir y comparar los marcos de trabajo de los estándares internacionales en gerencia de proyectos, que se encuentran en las principales agencias espaciales del mundo para luego identificar los procesos comunes en cada uno de estos. El producto de esta comparación contribuye a los procesos de gerencia de la metodología propuesta.

Actividades de la fase 1 :

- Identificar estándares existentes en gerencia de proyectos.

- Comparar los estándares existentes.

- Seleccionar los estándares aplicables al sector aeroespacial en Colombia.

- Incorporar los estándares seleccionados al marco de referencia.

Principales productos y resultados de la fase 1 :

- Listado de estándaresutilizados en la localización de las principales agencias del sector aeroespacial global.

- Listado de procesos en común de los estándares utilizados en la investigación.

\section{Fase 2. Analizar el sector aeroespacial en Colombia, en el área de gerencia de proyectos}

El objetivo de esta fase es recopilar toda la información alusiva al sector aeroespacial en Colombia, mediante una búsqueda sistémica que permita identificar 
los antecedentes, características y procesos particulares que se vienen aplicando en el marco singular de la gerencia de proyectos.

Actividades de la fase 2:

- Seleccionar las bases de datos y motores de búsqueda.

- Realizar una exploración bibliográfica con énfasis en la industria aeroespacial colombiana.

- Recopilar la información relevante para el sector aeroespacial.

- Analizar artículos seleccionados.

- Identificar las principales entidades del sector aeroespacial en Colombia.

- Realizar entrevistas o encuestas a las principales entidades del sector, con el fin de recolectar información adicional y los requerimientos de la gerencia de los proyectos internos.

- Integrar y sintetizar las características del sector aeroespacial en Colombia en el área de gerencia de proyectos.

Principales productos y resultados de la fase 2 :

- Análisis del sector aeroespacial en Colombia, en lo referente a la aplicación de prácticas en gerencia de proyectos.

\section{Fase 3. Diseñar la metodología para la gerencia de proyectos del sector aeroespacial en Colombia}

La finalidad de esta fase es integrar los resultados adquiridos en las fases 1 y 2 , para obtener una metodología que se adapte a las entidades del sector nacional, cumpla con las oportunas experiencias en gerencia internacional de proyectos $\mathrm{y}$, sirva de apoyo y complemento a los procesos internos de gerencia de cada organización.

Actividades de la fase 3 :

- Integración de fases 1 y 2.
- Realización de una metodología para la gestión de proyectos en Colombia con referencia al sector aeroespacial.

Principales productos y resultados de la fase 3 :

- Metodología para la gerencia de los proyectos aeroespaciales en Colombia.

\section{Fase 4. Validar la metodología}

Esta etapa se desarrolla con el objetivo de validar la metodología generada en la fase 3.

Actividades de la fase 4:

- Presentar la metodología a las principales entidades del sector.

- Recepción de comentariosy sugerencias por parte de los expertos de las entidades a través de encuestas, correo y reuniones virtuales.

- Incorporación de cambios a la metodología.

Principales productos y resultados de la fase 4:

- Metodología validada.

\section{Trabajo futuro}

La metodología aplicada se puede complementar con la inclusión de aquellos procesos de gerencia que fueron excluidos en este estudio, como por ejemplo, recopilar requisitos o validar el alcance.

La metodología usada en esta investigación se puede complementar con técnicas y herramientas vigentes, nacionales e internacionales en gerencia integral de proyectos. A su vez, entradas y salidas de los procesos se pueden desarrollar como complemento a este trabajo.

Así mismo, es posible indagar a mayor profundidad en las actividades específicas que desarrollan las entidades en la gerencia de los proyectos y, enlazar cada una de estas a los procesos propuestos en la metodología. 


\section{Resultados}

\section{Estándares internacionales en gerencia de proyectos}

Para establecer los estándares aplicados como referencia al desarrollo de esta metodología, en primera instancia se realizó una investigación acerca de las principales agencias aeroespaciales internacionales; luego, se tuvo en cuenta la ubicación geográfica de cada una de ellas y, por último, se relacionaron a los estándares de gerencia de proyectos implementados en esa región. Los resultados se ilustran en la tabla 1. No obstante, esto no implica que las principales agencias espaciales hagan uso exclusivo de los marcos de trabajo de la región.

Como se observa en la tabla anterior, los estándares usados en las zonas geográficas en donde están ubicadas las principales agencias aeroespaciales son PMBOK, АРMBOK, ICB, ISO 21500:2012 y P2M. Por tal motivo, se tuvieron en cuenta estos términos de referencia para la exposición de la metodología.

Más adelante, se realizó una comparación entre los procesos que se manejan en cada uno de los estándares, y como resultado de la comparación, resultaron 25 procesos que están presentes en todos los estándares tomados como referencia, detallado en la tabla 2.
Tabla 2

Procesos en común de los estándares internacionales

\begin{tabular}{|c|c|}
\hline & Procesos \\
\hline Gestión integración & Dirigir y gestionar el trabajo del proyecto \\
\hline & Gestionar el conocimiento del proyecto \\
\hline & Realizar el control integrado de cambios \\
\hline Gestión alcance & Definir el alcance \\
\hline & Crear la EDT/WBS \\
\hline & Controlar el alcance \\
\hline Gestión cronograma & Desarrollar el cronograma \\
\hline & Controlar el cronograma \\
\hline Gestión costos & Estimar los costos \\
\hline & Controlar los costos \\
\hline Gestión de la calidad & Planificar la gestión de la calidad \\
\hline & Gestionar la calidad \\
\hline Gestión de los recursos & Planificar la gestión de recursos \\
\hline & Estimar los recursos de las actividades \\
\hline & Dirigir al equipo \\
\hline & Controlar los recursos \\
\hline Gestión de las & Planificar la gestión de las comunicaciones \\
\hline comunicaciones & Gestionar las comunicaciones \\
\hline & Monitorear las comunicaciones \\
\hline Gestión de los riesgos & Identificar los riesgos \\
\hline & Implementar la respuesta a los riesgos \\
\hline & Monitorear los riesgos \\
\hline Gestión de las & Planificar la gestión de las adquisiciones \\
\hline & Controlar las adquisiciones \\
\hline Gestión de los interesados & Gestionar la participación de los interesados \\
\hline
\end{tabular}

Fuente: elaboración propia.

Tabla 1

Agencias espaciales y marco de trabajo en proyectos

\begin{tabular}{l|c|c|c|c|c|c|c|c} 
& \multicolumn{7}{c}{ Agencias espaciales más grandes del mundo } \\
\cline { 2 - 7 } & $\begin{array}{c}\text { National Aeronautics } \\
\text { and Space } \\
\text { Administration }\end{array}$ & $\begin{array}{c}\text { European } \\
\text { Space } \\
\text { Agency }\end{array}$ & $\begin{array}{c}\text { Canadian } \\
\text { Space } \\
\text { Agency }\end{array}$ & $\begin{array}{c}\text { China National } \\
\text { Space } \\
\text { Administration }\end{array}$ & $\begin{array}{c}\text { Russian Federal } \\
\text { Space Agency }\end{array}$ & $\begin{array}{c}\text { Centre National } \\
\text { d'Études Spatiales }\end{array}$ & $\begin{array}{c}\text { Agencia Japonesa } \\
\text { de Exploración } \\
\text { Aeroespacial }\end{array}$ \\
\hline País & NASA & ESA & ASC & CNSA & Roscosmos & CNES & JAXA \\
\hline Año & EE. UU. & Europa & Canadá & China & Rusia & Francia & Japón \\
\hline $\begin{array}{l}\text { Estándar } \\
\text { internacional } \\
\text { para proyectoS }\end{array}$ & PMI & 1962 & 1989 & 1993 & 1992 & 1961 & 2003 \\
\hline $\begin{array}{l}\text { Marco de } \\
\text { referencia }\end{array}$ & PMBOK & APM & PMI & IPMA & ISO & APM & PMAJ \\
\hline
\end{tabular}

Fuente: Cardoza y Guerrero (2011) e International Project Management Association (IPMA, 2016). 


\section{Descripción de estándares}

En la tabla 3, se realiza una descripción de los estándares seleccionados, junto con el respectivo marco de referencia y su definición de proyectos y gerencia de proyectos.

Tabla 3

Descripción de estándares

\section{Análisis del sector aeroespacial en Colombia en el área de gerencia de proyectos}

En la caracterización de la división aeroespacial colombiana se describe la evolución, estructura, procesos, entidades y regulación concerniente al sector

\begin{tabular}{|c|c|c|c|c|c|}
\hline ID & Estándar & Descripción & $\begin{array}{l}\text { Marco de } \\
\text { referencia }\end{array}$ & $\begin{array}{l}\text { Definición gerencia } \\
\text { de proyectos }\end{array}$ & Definición proyectos \\
\hline 1 & 1 & $\begin{array}{l}\text { IPMA fue la primera asociación de administración de } \\
\text { proyectos en el mundo. Fue fundada en 1965, en Viena, } \\
\text { Austria, con el objetivo de crear redes de cooperación y } \\
\text { trabajo para compartir información acerca de la gestión } \\
\text { de proyectos para luego ser registrada en Zúrich, Suiza, y } \\
\text { en Nijkerk, Holanda; es una asociación a nivel mundial que } \\
\text { cuenta hoy en día con más de } 50 \text { asociaciones nacionales } \\
\text { de gestión de proyectos, con más de } 40 \text { mil miembros } \\
\text { en todos los continentes, en su mayoría localizados } \\
\text { en Europa. IPMA se basa en la identificación de las } \\
\text { competencias necesarias para la dirección de proyectos. }\end{array}$ & $\begin{array}{l}\text { IPMA } \\
\text { Competence } \\
\text { Baseline (ICB3) }\end{array}$ & $\begin{array}{l}\text { Es la planificación, organización, } \\
\text { seguimiento y control de todos los } \\
\text { aspectos de un proyecto. }\end{array}$ & $\begin{array}{l}\text { Es una operación de } \\
\text { tiempo y costo limitados } \\
\text { para realizar un conjunto } \\
\text { de entregables definidos } \\
\text { (el alcance para cumplir } \\
\text { con los objetivos del } \\
\text { proyecto) hasta llegar } \\
\text { a los estándares de } \\
\text { calidad requeridos. }\end{array}$ \\
\hline 2 & $\begin{array}{l}\text { Project } \\
\text { Management } \\
\text { Institute. }\end{array}$ & $\begin{array}{l}\text { El Instituto de Gerencia de Proyectos (Project } \\
\text { Management Institute, PMI) es la organización de } \\
\text { gerencia de proyectos más grande del mundo, con } \\
\text { alrededor de } 280 \text { países asociados y cuya sede principal } \\
\text { se encuentra en Estados Unidos; tiene como objetivos } \\
\text { promover la profesión de dirección de proyectos, generar } \\
\text { conocimiento constante a través de la investigación y } \\
\text { generar estándares creados por la experiencia de sus } \\
\text { asociados sobre la gerencia de proyectos (PMI, 2016). }\end{array}$ & $\begin{array}{l}\text { Project } \\
\text { Management } \\
\text { Body of } \\
\text { Knowledge } \\
\text { (PMBoK) }\end{array}$ & $\begin{array}{l}\text { Aplicación de conocimientos, } \\
\text { habilidades, herramientas y } \\
\text { técnicas de actividades del } \\
\text { proyecto para cumplir con los } \\
\text { requisitos de este. }\end{array}$ & $\begin{array}{l}\text { Esfuerzo temporal que se } \\
\text { lleva a cabo para crear } \\
\text { un producto, servicio o } \\
\text { resultado único. }\end{array}$ \\
\hline 3 & PMAJ & $\begin{array}{l}\text { La Asociación de Gerencia de Proyectos del Japón (Project } \\
\text { Management Association of Japan, PMAJ) es una asociación } \\
\text { que se originó en noviembre del } 2005 \text { gracias a la unión de } \\
\text { dos organizaciones, el Project Management Professionals } \\
\text { Certification Center (PMCC) y el Japan Project Management } \\
\text { Forum (JPMF), las cuales buscaban mayor promoción de la } \\
\text { gerencia de proyectos en el país, satisfacer las necesidades } \\
\text { de educación y formación a los profesionales en gerencia } \\
\text { de proyectos y llevar a cabo una gran cantidad actividades } \\
\text { de alta calidad donde se pudiera crear una red personal y un } \\
\text { amplio conocimiento dentro y fuera de Japón. }\end{array}$ & $\begin{array}{l}\text { Project and } \\
\text { Program } \\
\text { Management } \\
\text { for Enterprise } \\
\text { Innovation } \\
\text { (P2M) }\end{array}$ & $\begin{array}{l}\text { La guía P2M se enfoca en la } \\
\text { organización y el programa, amplía el } \\
\text { alcance de los programas de gestión } \\
\text { de proyectos con la obtención de } \\
\text { beneficios para una organización, } \\
\text { así mismo sensibiliza la afectación } \\
\text { que pueden tener los proyectos por } \\
\text { procesos inesperados centrados en } \\
\text { la sociedad y el medio ambiente. El } \\
\text { profesional debe tener conocimiento } \\
\text { de múltiples disciplinas. }\end{array}$ & $\begin{array}{l}\text { Definen los proyectos } \\
\text { como un emprendimiento } \\
\text { de creación de valor } \\
\text { basado en una misión } \\
\text { de proyecto que es } \\
\text { completado en un } \\
\text { marco de tiempo } \\
\text { dado u acordado y } \\
\text { bajo restricciones, } \\
\text { incluidos los recursos y } \\
\text { circunstancias externas. }\end{array}$ \\
\hline 4 & APM & $\begin{array}{l}\text { La Asociación para la Gerencia de Proyectos (Association } \\
\text { for Project Management, APM) es una asociación que } \\
\text { cuenta con más de } 21.650 \text { profesionales y más de } 570 \\
\text { miembros corporativos, siendo la más grande de Europa } \\
\text { en gerencia de proyectos; la misión de la asociación es } \\
\text { proveer liderazgo a las organizaciones e individuos que } \\
\text { estén dispuestos a compartir su pasión por la mejora de } \\
\text { los resultados de los proyectos. }\end{array}$ & $\begin{array}{l}\text { APM Body of } \\
\text { Knowledge } \\
\text { (Cuerpo de } \\
\text { conocimiento } \\
\text { de la APM) }\end{array}$ & $\begin{array}{l}\text { La gestión de proyectos es el } \\
\text { proceso mediante el cual los } \\
\text { proyectos se definen, planifican, } \\
\text { supervisan, controlan y entregan de } \\
\text { modo que los beneficios acordados } \\
\text { se realicen. }\end{array}$ & $\begin{array}{l}\text { Un esfuerzo único y } \\
\text { transitorio emprendido } \\
\text { para lograr un resultado. }\end{array}$ \\
\hline 5 & ISO 21500 & $\begin{array}{l}\text { La organización Internacional de Normalización } \\
\text { (International Organization for Standardization, ISO) es } \\
\text { una organización no gubernamental internacional e } \\
\text { independiente, que comenzó en febrero de } 1947 \text { gracias a } \\
\text { algunos delegados de países que se reunieron en Londres } \\
\text { con el objetivo de facilitar la coordinación internacional y } \\
\text { la unificación de las normas industriales; en la actualidad, } \\
\text { la Iso tiene su centro de operaciones en Ginebra, Suiza, y } \\
\text { posee más de } 162 \text { países miembros. La ISO a través de sus } \\
\text { miembros y sus expertos, busca compartir conocimiento y } \\
\text { desarrollar estrategias basadas en consenso, con normas } \\
\text { internacionales que soporten la innovación y provean } \\
\text { soluciones a los desafíos globales. }\end{array}$ & $\begin{array}{l}\text { ISO 21500:2012 } \\
\text { “Orientación } \\
\text { sobre gerencia } \\
\text { de proyectos" }\end{array}$ & $\begin{array}{l}\text { La gestión de proyectos es } \\
\text { la aplicación de métodos, } \\
\text { herramientas, técnicas y } \\
\text { competencias para un proyecto. }\end{array}$ & $\begin{array}{l}\text { Un proyecto consiste } \\
\text { en un conjunto único de } \\
\text { procesos y actividades } \\
\text { coordinadas y } \\
\text { controladas con fechas } \\
\text { de inicio y finalización, } \\
\text { realizadas para alcanzar } \\
\text { los objetivos del proyecto. }\end{array}$ \\
\hline
\end{tabular}

Fuente: Murray-Webster y Dalcher (2019), IPMA (2016), Iso (2012), Apmbok (2019)

y $\mathrm{P} 2 \mathrm{M}$ (2016). 
aeroespacial en el país. Además, se conocieron las principales empresas dedicadas a esta actividad económica y se identificaron las prácticas relacionadas con la gestión de proyectos aplicados en este sector.

Las organizaciones aeroespaciales en Colombia se distribuyen en diferentes categorías, según su actividad en el sector: transporte aéreo; aviación especializada; educación; estructuras; hidráulicos y motores; talleres aeronáuticos de reparación (TAR-OMA); suministros; fabricación; ciencia y tecnología; proveedores y aliados, y aviónica, como se muestra en la siguiente ilustración:
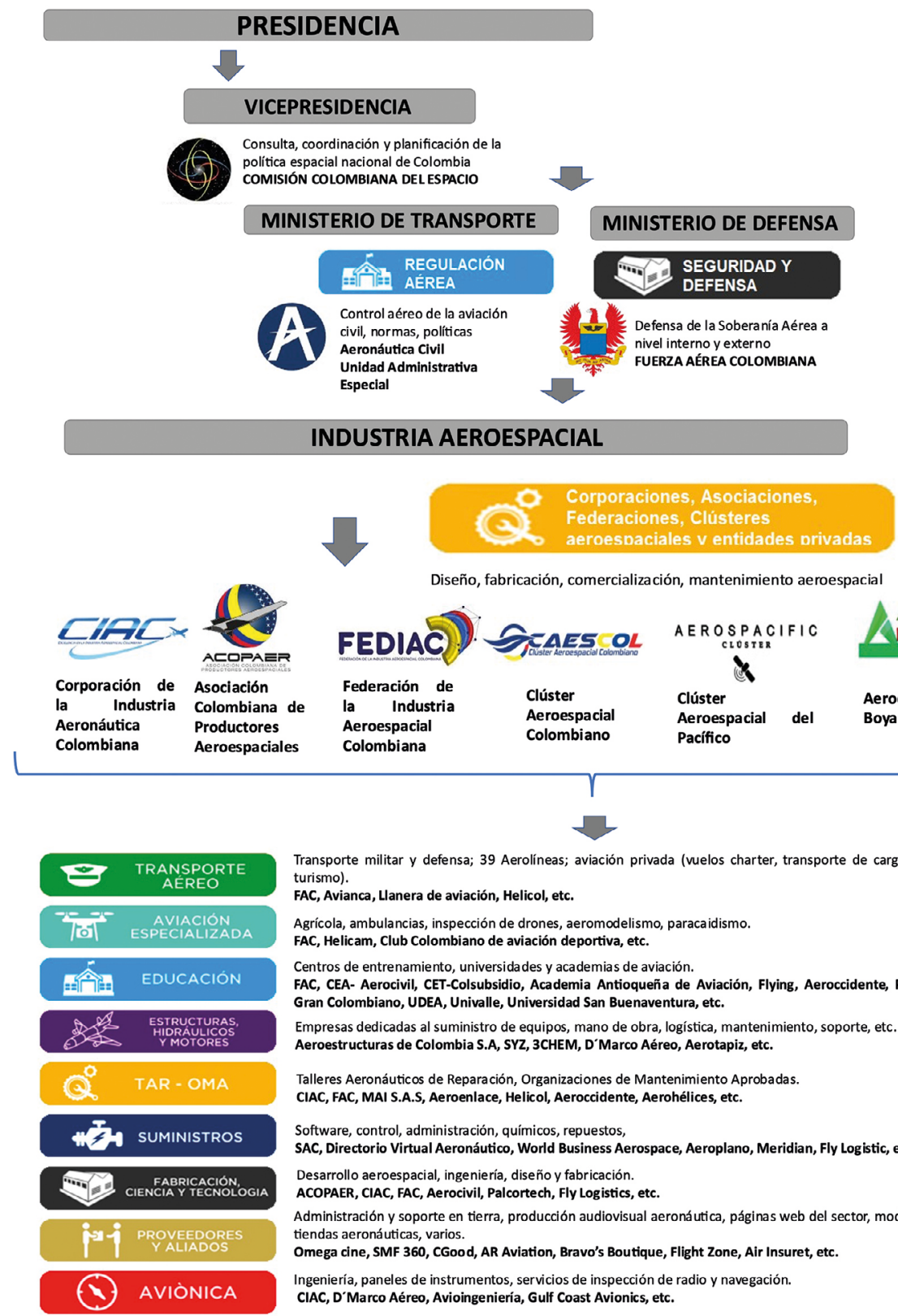

Diseño, fabricación, comercialización, mantenimiento aeroespacial
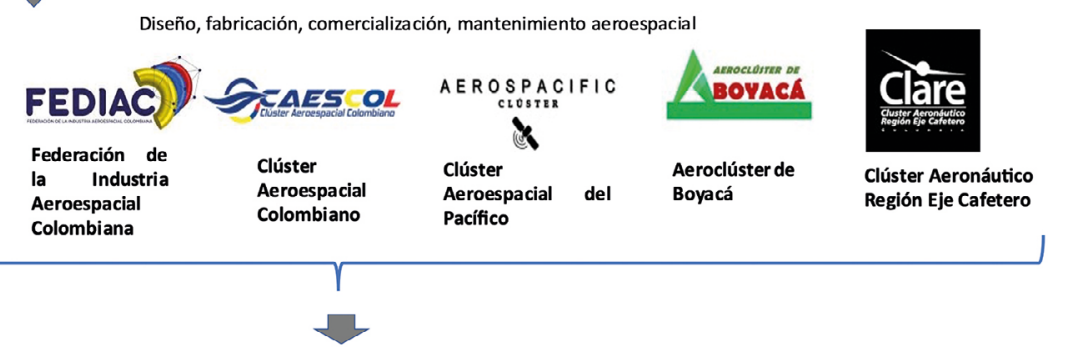

Figura 1. Estructura y empresas del sector aeroespacial en Colombia

Fuente: Gestión pública (2020). 
Con el objetivo de seleccionar las organizaciones con mayor influencia en el sector aeroespacial colombiano, se tomó como referencia los ingresos reportados en el estado de resultados de cada entidad y se compararon las empresas del sector mediante un diagrama de Pareto.

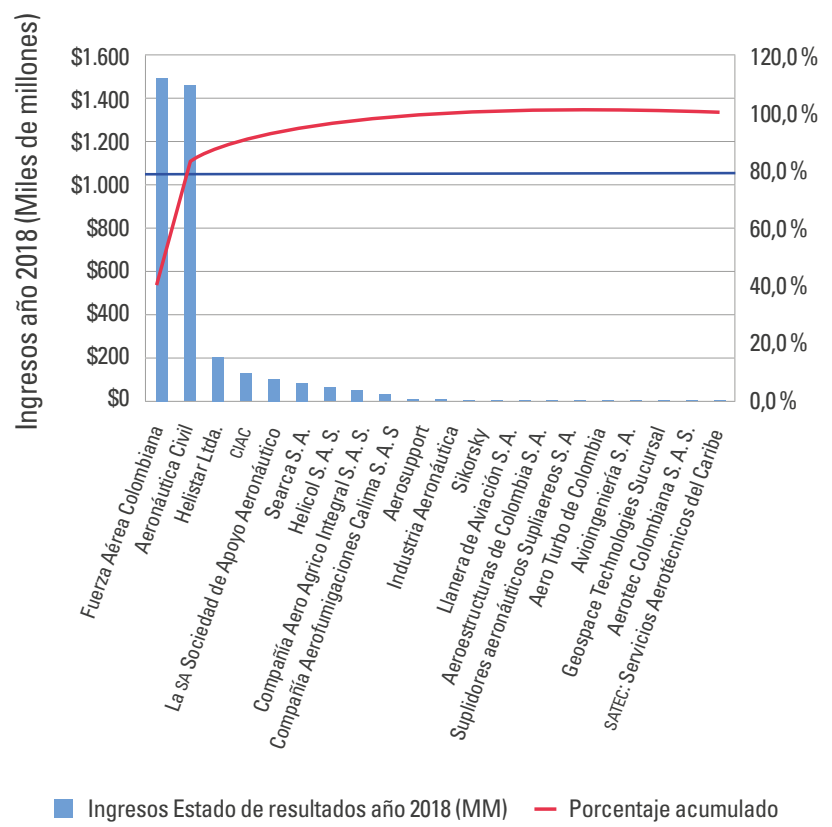

Figura 2. Pareto del sector aeroespacial en Colombia Fuente: Supersociedades (2020).

Al realizar la comparación de los ingresos obtenidos por las organizaciones más representativas del sector aeroespacial en Colombia, se tomó una muestra de 20 empresas nacionales enfocadas en la industria. A este respecto, la gráfica de Pareto indica que, de los ingresos en sus estados de resultados, la fac y la Aeronáutica Civil (Aerocivil), representan un 83,5\% del total, así mismo, este porcentaje representa el $10 \%$ de las entidades tomadas como muestra, lo que indica que la FAC y la Aerocivil son las dos organizaciones más influyentes (FAC, 2018).

De igual modo, se identificó que la importancia de la Aerocivil y la FAC en el sector aeroespacial radica en que dichas entidades son la Autoridad de Aviación Civil y la Autoridad de Aviación Militar en Colombia, por lo cual, son referentes para las políticas e instancias que rigen al sector en el país (Granada et al., 2017).
Lo anterior, está alineado con el resultado encontrado en el análisis de Pareto visto en la figura 2.

En ese marco, se indagó en los procesos de gestión implementados en los proyectos de cada una de las entidades (Aerocivil, 2019).

\section{Gerencia de proyectos del sector aeroespacial en Colombia}

Para identificar la gerencia de proyectos del sector en las entidades seleccionadas, se realizaron entrevistas y visitas a la Dirección de Ciencia, Tecnología e Innovación (Dicti) de la FAC y a la Unidad de I+D+i de la Aerocivil, encargadas de los proyectos.

En el ejercicio de recopilación de información, se obtuvieron datos específicos sobre los procesos, actividades, plantillas, formatos, instructivos y flujos de procesos implantados en la gerencia de proyectos de cada organización.

\section{Procesos de gerencia Aerocivil}

A continuación se relacionan los procesos de gerencia que se utilizan actualmente en los proyectos de la Aerocivil y, la verificación de si existe algún procedimiento o formato específico para esta función.

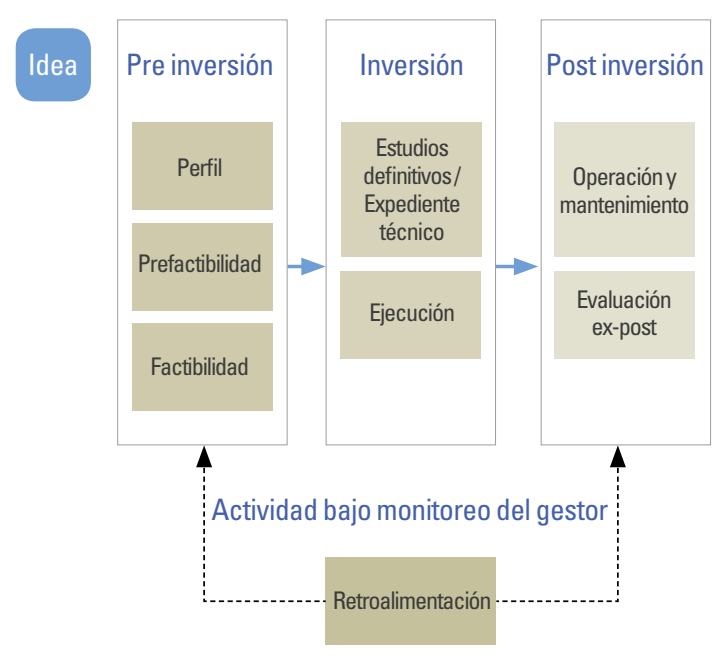

Figura 3. Procesos de gerencia Aerocivil

Fuente: Aerocivil (2021). 
Tabla 4

Procesos de gerencia en proyectos de la Aerocivil

\begin{tabular}{|c|c|c|c|c|}
\hline & Procesos & ¿Se realiza este proceso? & $\begin{array}{l}\text { ¿Tiene un formato } \\
\text { específico? }\end{array}$ & $\begin{array}{l}\text { ¿Se tiene un procedimiento } \\
\text { de instrucciones } \\
\text { para este proceso? }\end{array}$ \\
\hline $\begin{array}{l}\text { Gestión } \\
\text { Integración }\end{array}$ & $\begin{array}{l}\text { Dirigir y gestionar el trabajo del proyecto } \\
\text { Gestionar el conocimiento del proyecto } \\
\text { Realizar el control integrado de cambios }\end{array}$ & $\begin{array}{l}\text { Sí } \\
\text { Sí } \\
\text { No }\end{array}$ & $\begin{array}{l}\text { No } \\
\text { No } \\
\text { No }\end{array}$ & $\begin{array}{l}\text { No } \\
\text { No } \\
\text { No }\end{array}$ \\
\hline Gestión Alcance & $\begin{array}{l}\text { Definir el alcance } \\
\text { Crear la EDT/WBS } \\
\text { Controlar el alcance }\end{array}$ & $\begin{array}{l}\text { Sí } \\
\text { No } \\
\text { No }\end{array}$ & $\begin{array}{l}\text { Sí } \\
\text { No } \\
\text { No }\end{array}$ & $\begin{array}{l}\text { Sí } \\
\text { No } \\
\text { No }\end{array}$ \\
\hline $\begin{array}{l}\text { Gestión del } \\
\text { Cronograma }\end{array}$ & $\begin{array}{l}\text { Desarrollar el cronograma } \\
\text { Controlar el cronograma }\end{array}$ & $\begin{array}{l}\text { Sí } \\
\text { Sí }\end{array}$ & $\begin{array}{l}\text { No } \\
\text { No }\end{array}$ & $\begin{array}{l}\text { No } \\
\text { No }\end{array}$ \\
\hline $\begin{array}{l}\text { Gestión de } \\
\text { Costos }\end{array}$ & $\begin{array}{l}\text { Estimar los costos } \\
\text { Controlar los costos }\end{array}$ & $\begin{array}{l}\text { Sí } \\
\text { Sí }\end{array}$ & $\begin{array}{l}\text { Sí } \\
\text { No }\end{array}$ & $\begin{array}{l}\text { Sí } \\
\text { No }\end{array}$ \\
\hline $\begin{array}{l}\text { Gestión de } \\
\text { la Calidad }\end{array}$ & $\begin{array}{l}\text { Planificar la gestión de la calidad } \\
\text { Gestionar la calidad } \\
\text { Planificar la gestión de recursos }\end{array}$ & $\begin{array}{l}\text { Sí } \\
\text { Sí } \\
\text { Sí }\end{array}$ & $\begin{array}{l}\text { Sí } \\
\text { Sí } \\
\text { Sí }\end{array}$ & $\begin{array}{l}\text { Sí } \\
\text { Sí } \\
\text { Sí }\end{array}$ \\
\hline $\begin{array}{l}\text { Gestión de } \\
\text { los Recursos }\end{array}$ & $\begin{array}{l}\text { Estimar los recursos de las actividades } \\
\text { Dirigir al equipo } \\
\text { Controlar los recursos }\end{array}$ & $\begin{array}{l}\text { Sí } \\
\text { Sí } \\
\text { Sí }\end{array}$ & $\begin{array}{l}\text { Sí } \\
\text { No } \\
\text { Sí }\end{array}$ & $\begin{array}{l}\text { Sí } \\
\text { No } \\
\text { Sí }\end{array}$ \\
\hline $\begin{array}{l}\text { Gestión de las } \\
\text { Comunicaciones }\end{array}$ & $\begin{array}{l}\text { Planificar la gestión de las comunicaciones } \\
\text { Gestionar las comunicaciones } \\
\text { Monitorear las comunicaciones }\end{array}$ & $\begin{array}{l}\text { Sí } \\
\text { Sí } \\
\text { No }\end{array}$ & $\begin{array}{l}\text { No } \\
\text { No } \\
\text { No }\end{array}$ & $\begin{array}{l}\text { No } \\
\text { No } \\
\text { No }\end{array}$ \\
\hline $\begin{array}{l}\text { Gestión de } \\
\text { los Riesgos }\end{array}$ & $\begin{array}{l}\text { Identificar los riesgos } \\
\text { Implementar la respuesta a los riesgos } \\
\text { Monitorear los riesgos }\end{array}$ & $\begin{array}{l}\text { Sí } \\
\text { Sí } \\
\text { Sí }\end{array}$ & $\begin{array}{l}\text { Sí } \\
\text { Sí } \\
\text { Sí }\end{array}$ & $\begin{array}{l}\text { Sí } \\
\text { Sí } \\
\text { Sí }\end{array}$ \\
\hline $\begin{array}{l}\text { Gestión de las } \\
\text { Adquisiciones }\end{array}$ & $\begin{array}{l}\text { Planificar la gestión de las adquisiciones } \\
\text { Controlar las adquisiciones }\end{array}$ & $\begin{array}{l}\text { Sí } \\
\text { Sí }\end{array}$ & $\begin{array}{l}\text { Sí } \\
\text { Sí }\end{array}$ & $\begin{array}{l}\text { Sí } \\
\text { Sí }\end{array}$ \\
\hline
\end{tabular}

Fuente: Aerocivil (2020).

\section{Procesos de gerencia FAC}

A continuación, se relacionan los procesos de gerencia utilizados en los proyectos de la FAC y, la verificación de si existe algún procedimiento o formato específico para esta función (FAC, 2020).
Figura 4 . Flujo de procesos de gerencia FAC Fuente: (FAC, 2021).

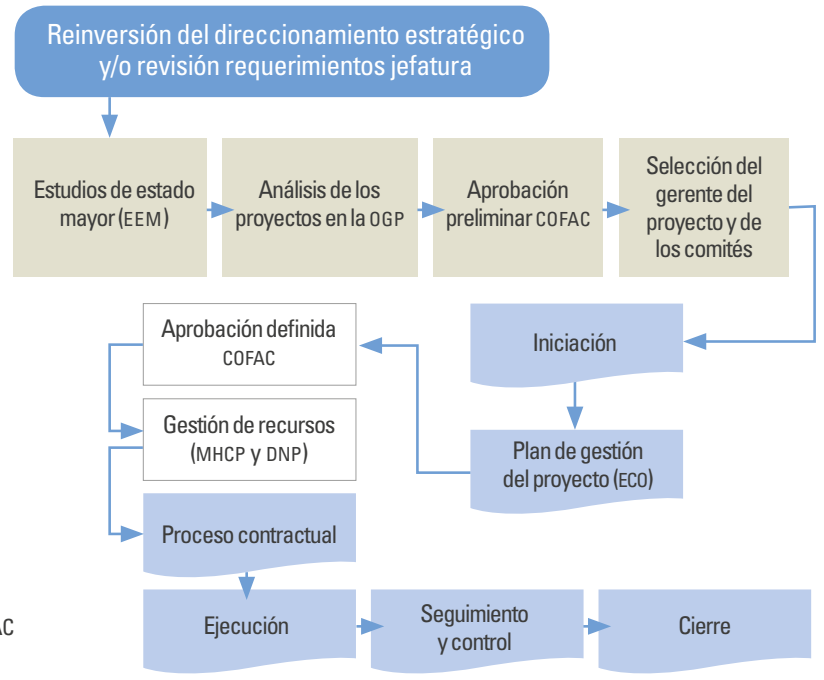


Tabla 5

Procesos de gerencia en proyectos de la FAC

\begin{tabular}{|c|c|c|c|c|}
\hline & Procesos & ¿Se realiza este proceso? & $\begin{array}{l}\text { ¿Tiene un formato } \\
\text { específico? }\end{array}$ & $\begin{array}{l}\text { ¿Se tiene un procedimiento } \\
\text { de instrucciones } \\
\text { para este proceso? }\end{array}$ \\
\hline $\begin{array}{l}\text { Gestión } \\
\text { Integración }\end{array}$ & $\begin{array}{l}\text { Dirigir y gestionar el trabajo del proyecto } \\
\text { Gestionar el conocimiento del proyecto } \\
\text { Realizar el control integrado de cambios }\end{array}$ & $\begin{array}{l}\text { Sí } \\
\text { Sí } \\
\text { Sí }\end{array}$ & $\begin{array}{l}\text { Sí } \\
\text { Sí } \\
\text { Sí }\end{array}$ & $\begin{array}{l}\text { Sí } \\
\text { Sí } \\
\text { Sí }\end{array}$ \\
\hline Gestión Alcance & $\begin{array}{l}\text { Definir el alcance } \\
\text { Crear la EDT/WBS } \\
\text { Controlar el alcance }\end{array}$ & $\begin{array}{l}\text { No } \\
\text { Sí } \\
\text { No }\end{array}$ & $\begin{array}{l}\text { No } \\
\text { Sí } \\
\text { No }\end{array}$ & $\begin{array}{l}\text { No } \\
\text { Sí } \\
\text { No }\end{array}$ \\
\hline $\begin{array}{l}\text { Gestión del } \\
\text { Cronograma }\end{array}$ & $\begin{array}{l}\text { Desarrollar el cronograma } \\
\text { Controlar el cronograma }\end{array}$ & $\begin{array}{l}\text { Sí } \\
\text { Sí }\end{array}$ & $\begin{array}{l}\text { Sí } \\
\text { Sí }\end{array}$ & $\begin{array}{l}\text { Sí } \\
\text { Sí }\end{array}$ \\
\hline $\begin{array}{l}\text { Gestión de } \\
\text { Costos }\end{array}$ & $\begin{array}{l}\text { Estimar los costos } \\
\text { Controlar los costos }\end{array}$ & $\begin{array}{l}\text { Sí } \\
\text { Sí }\end{array}$ & $\begin{array}{l}\text { Sí } \\
\text { Sí }\end{array}$ & $\begin{array}{l}\text { Sí } \\
\text { Sí }\end{array}$ \\
\hline $\begin{array}{l}\text { Gestión de } \\
\text { la Calidad }\end{array}$ & $\begin{array}{l}\text { Planificar la gestión de la calidad } \\
\text { Gestionar la calidad }\end{array}$ & $\begin{array}{l}\text { No } \\
\text { No }\end{array}$ & $\begin{array}{l}\text { No } \\
\text { No }\end{array}$ & $\begin{array}{l}\text { No } \\
\text { No }\end{array}$ \\
\hline $\begin{array}{l}\text { Gestión de I } \\
\text { os Recursos }\end{array}$ & $\begin{array}{l}\text { Planificar la gestión de recursos } \\
\text { Estimar los recursos de las actividades } \\
\text { Dirigir al equipo } \\
\text { Controlar los recursos }\end{array}$ & $\begin{array}{l}\text { Sí } \\
\text { Sí } \\
\text { Sí } \\
\text { Sí }\end{array}$ & $\begin{array}{l}\text { Sí } \\
\text { Sí } \\
\text { Sí } \\
\text { Sí }\end{array}$ & $\begin{array}{l}\text { Sí } \\
\text { Sí } \\
\text { Sí } \\
\text { Sí }\end{array}$ \\
\hline $\begin{array}{l}\text { Gestión de las } \\
\text { Comunicaciones }\end{array}$ & $\begin{array}{l}\text { Planificar la gestión de las comunicaciones } \\
\text { Gestionar las comunicaciones } \\
\text { Monitorear las comunicaciones }\end{array}$ & $\begin{array}{l}\text { Sí } \\
\text { Sí } \\
\text { No }\end{array}$ & $\begin{array}{l}\text { Sí } \\
\text { Sí } \\
\text { No }\end{array}$ & $\begin{array}{l}\text { Sí } \\
\text { Sí } \\
\text { No }\end{array}$ \\
\hline $\begin{array}{l}\text { Gestión de } \\
\text { los Riesgos }\end{array}$ & $\begin{array}{l}\text { Identificar los riesgos } \\
\text { Implementar la respuesta a los riesgos } \\
\text { Monitorear los riesgos }\end{array}$ & $\begin{array}{c}\text { Sí } \\
\text { No } \\
\text { No }\end{array}$ & $\begin{array}{l}\text { Sí } \\
\text { No } \\
\text { No }\end{array}$ & $\begin{array}{l}\text { Sí } \\
\text { No } \\
\text { No }\end{array}$ \\
\hline $\begin{array}{l}\text { Gestión de las } \\
\text { Adquisiciones }\end{array}$ & $\begin{array}{l}\text { Planificar la gestión de las adquisiciones } \\
\text { Controlar las adquisiciones }\end{array}$ & $\begin{array}{l}\text { Sí } \\
\text { Sí }\end{array}$ & $\begin{array}{l}\text { Sí } \\
\text { Sí }\end{array}$ & $\begin{array}{l}\text { Sí } \\
\text { Sí }\end{array}$ \\
\hline $\begin{array}{l}\text { Gestión de los } \\
\text { Interesados }\end{array}$ & $\begin{array}{l}\text { Gestionar la participación } \\
\text { de los interesados }\end{array}$ & Sí & Sí & Sí \\
\hline
\end{tabular}

Fuente: (FAC, 2020).

Durante la encuesta realizada a las entidades del sector, se evidenció que hay procesos que se están ejecutando, pero no se encuentran dentro de los procesos filtrados. Estos 11 procesos se incluyen en el desarrollo de esta metodología para complementar y fortalecer la estructura de los procesos de gerencia.
Teniendo en cuenta los procesos que se realizan en cada entidad, se evidenció que la FAC no lleva a cabo los procesos de definición y control del alcance; planificación y gestión de la calidad; ejecución de la respuesta a los riesgos y su monitoreo, y el control de las comunicaciones. Por otro lado, la Aerocivil no lleva

Tabla 6

Procesos de gerencia adicionales utilizados por los principales entes del sector

\begin{tabular}{l|l}
\hline \multicolumn{1}{c|}{ Área de Conocimiento } & \multicolumn{1}{c}{ Proceso } \\
\hline Gestión de la integración & Desarrollar acta de constitución del proyecto \\
\hline Gestión de la integración & $\begin{array}{l}\text { Desarrollar el plan para la dirección } \\
\text { del proyecto }\end{array}$ \\
\hline Gestión de la integración & Monitorear y controlar el trabajo del proyecto \\
\hline Gestión de la integración & Cerrar el proyecto o fase \\
\hline Gestión del cronograma & Estimar duración de las actividades \\
\hline
\end{tabular}

\begin{tabular}{l|l}
\multicolumn{1}{c|}{ Área de Conocimiento } & \multicolumn{1}{c}{ Proceso } \\
\hline Gestión de la calidad & Controlar la calidad \\
\hline Gestión de los riesgos & Realizar análisis cualitativo de riesgos \\
\hline Gestión de los interesados & Identificar a los interesados \\
\hline Gestión de la integración & Aprobar definitivamente la planeación \\
\hline Gestión del costos & Determinar el presupuesto \\
\hline Gestión del cronograma & Definir y secuenciar las actividades
\end{tabular}

Fuente: Aerocivil (2019) 
a cabo los procesos de realizar el control integrado de cambios; crear la EDT; manejar el alcance; gestionar la intervención de los interesados y el monitoreo de las comunicaciones (Monsalve, 2019).
Dentro las organizaciones existen responsables para cada proceso de gerencia. De modo tal que se identificó el área responsable y el cargo que desarrolla dentro de la Aerocivil y la FAC cada funcionario.

Tabla 7

Responsables de los procesos de gerencia dentro de los entes del sector aeroespacial

Área responsable o cargo que desarrolla este proceso

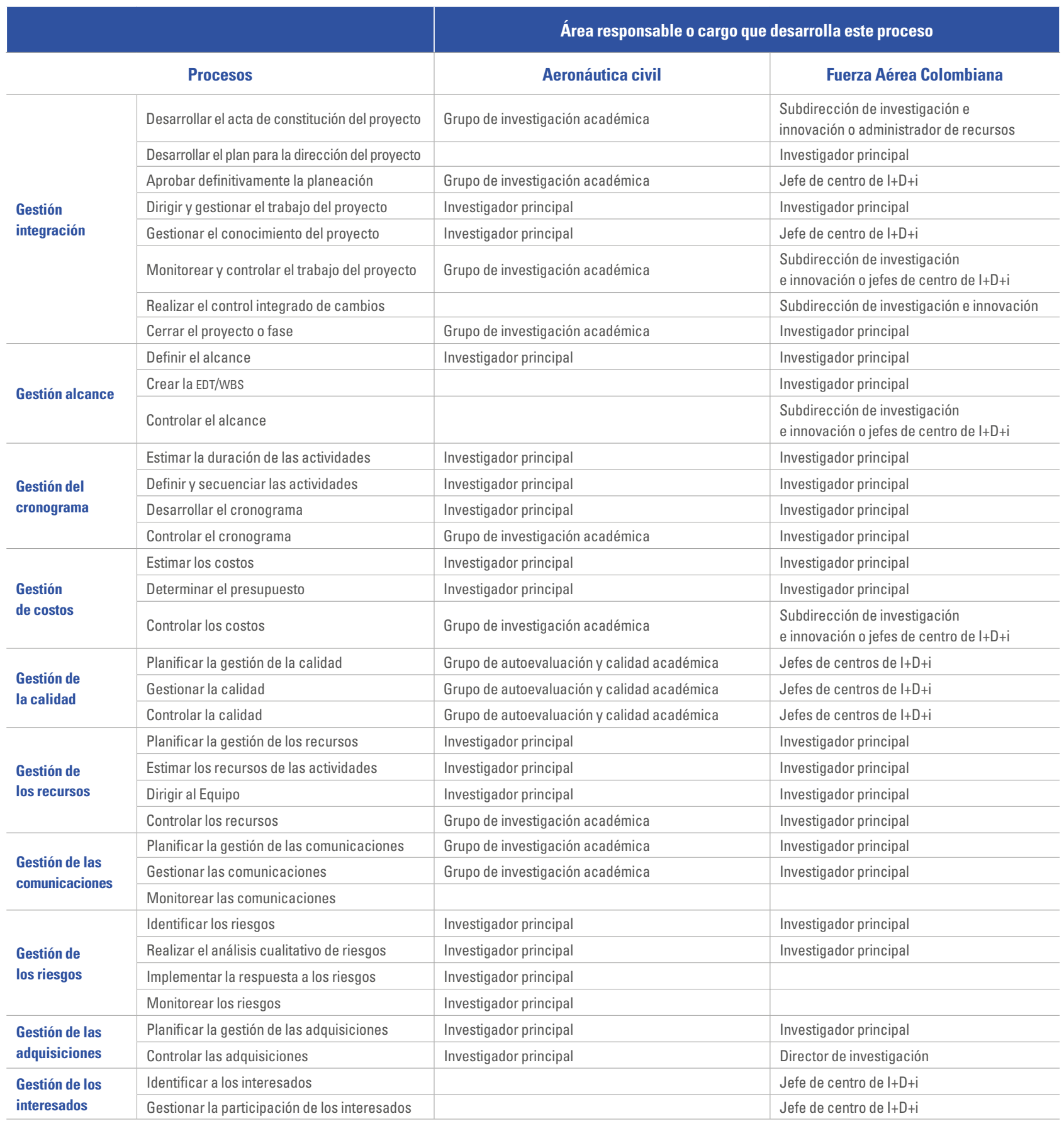

Fuente: Aerocivil (2020) 
Así, se identificaron 36 procesos para la gerencia de proyectos del sector aeroespacial en Colombia. Cada uno de estos, con su respectivo procedimiento y formato.

Tabla 8

Procesos de gerencia identificados

\begin{tabular}{|c|c|}
\hline & Procesos \\
\hline Gestión & Desarrollar el acta de constitución del proyecto \\
\hline & Desarrollar el plan para la dirección del proyecto \\
\hline & Aprobar definitivamente la planeación \\
\hline & Dirigir y gestionar el trabajo del proyecto \\
\hline & Gestionar el conocimiento del proyecto \\
\hline & Monitorear y controlar el trabajo del proyecto \\
\hline & Realizar el control integrado de cambios \\
\hline & Cerrar el proyecto o fase \\
\hline Gestión alcance & Definir el alcance \\
\hline & Crear la EDT/WBS \\
\hline & Controlar el alcance \\
\hline Gestión del & Estimar la duración de las actividades \\
\hline cronograma & Definir y secuenciar las actividades \\
\hline & Desarrollar el cronograma \\
\hline & Controlar el cronograma \\
\hline Gestión & Estimar los costos \\
\hline de costos & Determinar el presupuesto \\
\hline & Controlar los costos \\
\hline Gestión de & Planificar la gestión de la calidad \\
\hline & Gestionar la calidad \\
\hline & Controlar la calidad \\
\hline Gestión de & Planificar la gestión de los recursos \\
\hline los recursos & Estimar los recursos de las actividades \\
\hline & Dirigir al equipo \\
\hline & Controlar los recursos \\
\hline Gestión de las & Planificar la gestión de las comunicaciones \\
\hline comunicaciones & Gestionar las comunicaciones \\
\hline & Monitorear las comunicaciones \\
\hline Gestión de & Identificar los riesgos \\
\hline los riesgos & Realizar el análisis cualitativo de riesgos \\
\hline & Implementar la respuesta a los riesgos \\
\hline & Monitorear los riesgos \\
\hline Gestión de las & Planificar la gestión de las adquisiciones \\
\hline adquisiciones & Controlar las adquisiciones \\
\hline Gestión de los & Identificar a los interesados \\
\hline & Gestionar la participación de los interesados \\
\hline
\end{tabular}

Fuente: elaboración propia.

\section{Desarrollo de la metodología}

La metodología comprende seis diagramas, uno por cada agrupación de procesos (iniciación, planeación, ejecución, seguimiento y finalización); y uno general, en el que se relacionan estos grupos de procesos. A su vez, la metodología contiene 36 procedimientos, uno por cada proceso resultado de la sección dos y tres de este documento. También incluye un formato por cada procedimiento en el que se relaciona lo descrito para facilitar la ejecución de del proceso.

\section{Codificación de diagramas de flujo, procesos y formatos}

La metodología maneja una codificación para los diagramas de flujo, procesos y formatos. A continuación, se presenta el respectivo método de identificación. A cada uno de los grupos de procesos se le asignó un código de identificación y un color (usado en los bordes de los procedimientos $y$ formatos).

Tabla 9

Codificación procesos

\begin{tabular}{c|c|c}
\hline Código de identificación & Descripción & Color \\
\hline PI & Inicio & Rojo \\
\hline PP & Planeación & Amarillo \\
\hline PE & Ejecución & Verde \\
\hline PM & Monitoreo y control & Azul \\
\hline PC & Cierre & Morado \\
\hline
\end{tabular}

Fuente: elaboración propia.

A cada grupo del proceso se le asignó un consecutivo de dos dígitos:

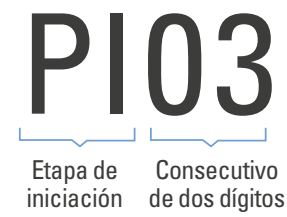

Figura 5 . Ejemplo codificación procesos

Fuente: elaboración propia. 
Para la correcta interrelación entre procesos se elaboraron seis diagramas de flujo. El primero es general y agrupa los procesos de inicio, planeación, ejecución, monitoreo y cierre. Los otros cinco diagramas son específicos para cada grupo. La identificación de estos se referencia en la tabla 10.

Tabla 10

Codificación diagramas de flujo

\begin{tabular}{c|l}
\hline Código de identificación & \multicolumn{1}{c}{ Descripción } \\
\hline DFI & Diagrama de flujo inicio \\
\hline DFP & Diagrama de flujo planeación \\
\hline DFE & Diagrama de flujo ejecución \\
\hline DFM & Diagrama de flujo monitoreo/control \\
\hline DFC & Diagrama de flujo cierre \\
\hline DFG & Diagrama de flujo general \\
\hline
\end{tabular}

Fuente: elaboración propia.

Para los 36 procesos de la metodología, se incluyó un formato que relaciona la información comprendida en los procedimientos y facilita la organización y registro de la información generada. La identificación de estos, se muestra en la tabla 11. Luego del código de identificación, el formato llevará el mismo consecutivo del procedimiento al cual pertenece. Para cada uno de los procesos, se inicia con la identificación del grupo, seguido de un consecutivo.

Tabla 11

Codificación formatos

\begin{tabular}{c|l}
\hline Código de identificación & \multicolumn{1}{|c}{ Descripción } \\
\hline FI & Formato de inicio \\
\hline FP & Formato de planeación \\
\hline FE & Formato de ejecución \\
\hline FM & Formato de monitoreo/control \\
\hline FC & Formato de cierre \\
\hline
\end{tabular}

Fuente: elaboración propia.

\section{Diagramas de flujo}

Los diagramas representan la secuencia del trabajo para la gerencia de proyectos en el sector. En este caso se evidencia la manera como se conectan los procesos entre sí. Ya que en muchos de estos, es necesario tener la información obtenida como resultado de otro proceso. Por ello, se recomienda que antes de realizar cualquier procedimiento se siga el orden lógico para garantizar que en ese punto del proyecto se cuente con la información necesaria para ejecutar dicho proceso. Cada uno de los símbolos usados en los diagramas de flujo se menciona a continuación:

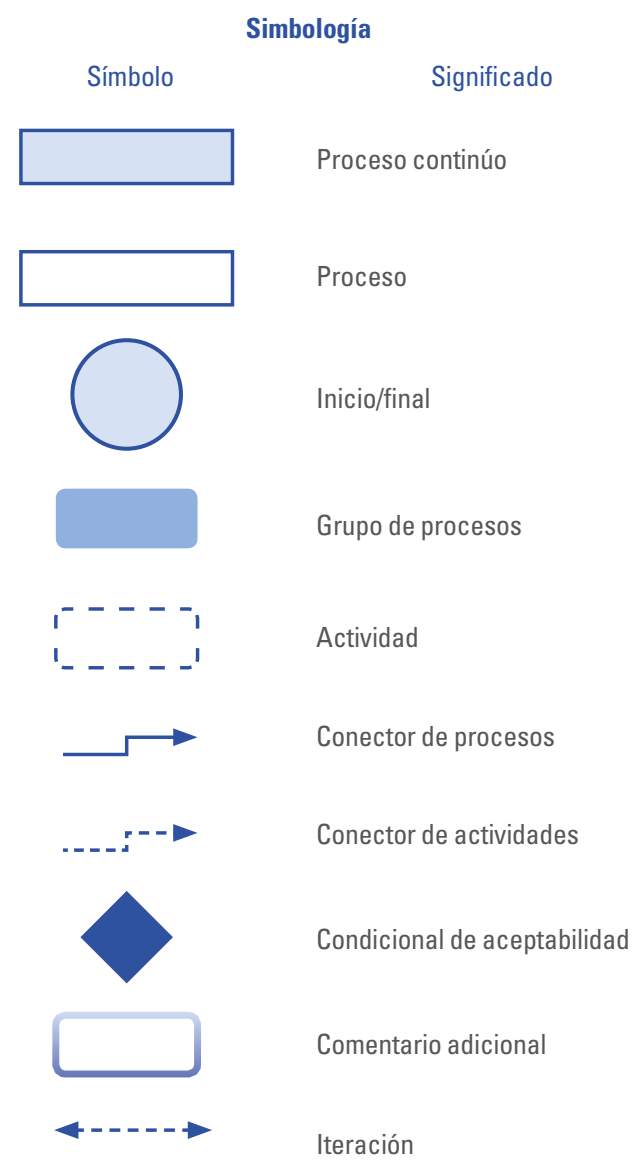

Figura 6. Simbología de los diagramas de flujo Fuente: elaboración propia.

Se recomienda hacer uso del formato de manera simultánea, de acuerdo con el consecutivo de los grupos de procesos, debido a que cada procedimiento se encuentra articulado con un formato. En el caso de que los procedimientos no requieran de registro, en la columna de "ID Formato" y "Nombre formato" se registra como "No Aplica - NA". 


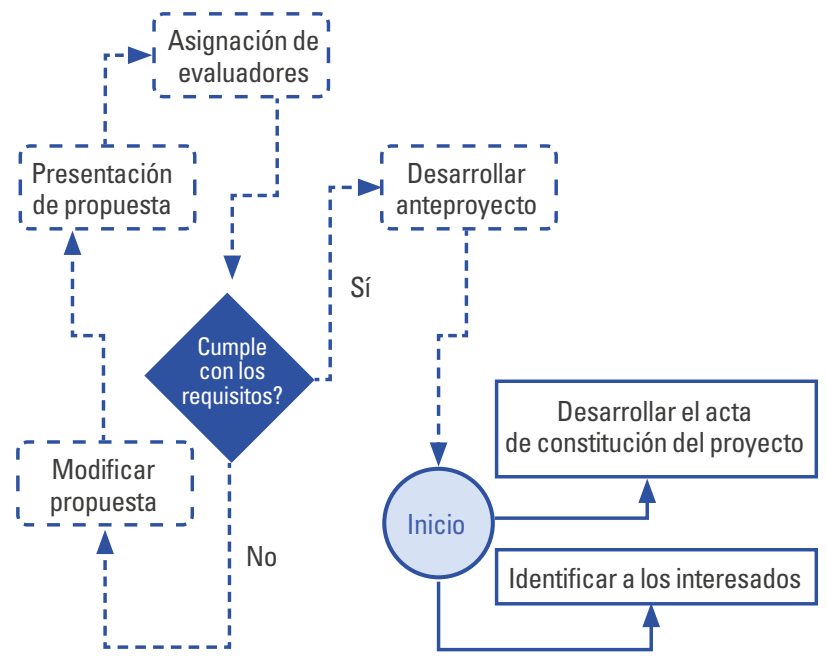

Figura 7. Ejemplo de diagrama de flujo del grupo de procesos de inicio Fuente: elaboración propia.

\section{Procedimientos y formatos}

Los procedimientos y formatos son herramientas de la metodología con las que se pueden desarrollar proyectos de las organizaciones aeroespaciales. Los procedimientos cuentan con un número de identificación, la descripción del procedimiento, el responsable y el respectivo nombre del formato como se detalla:

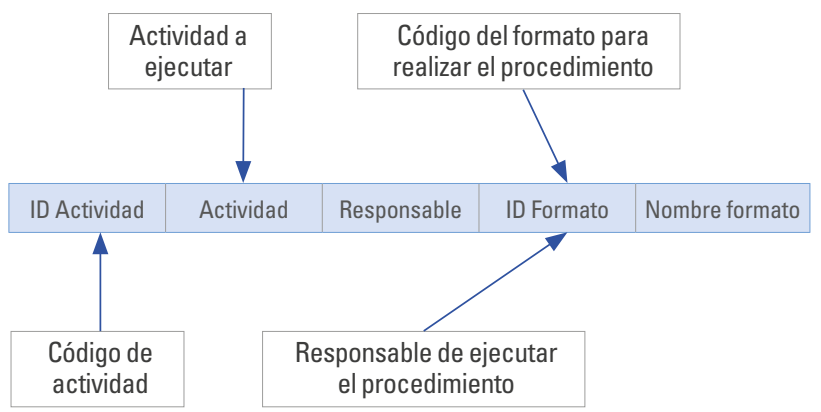

Figura 8. Detalle del formato de los procedimientos

Fuente: elaboración propia.

Los procedimientos de cada proceso indican el marco de trabajo a seguir para completar su respectivo formato. Cada uno de los procesos seleccionados para la metodología tiene su debido procedimiento, una sinergia de los procedimientos propios del sector aeroespacial y la metodología desarrollada (Suárez, 2020).
Tabla 12

Ejemplo del procedimiento del proceso “Desarrollar el acta de constitución del proyecto". Grupo de procesos de inicio

PI01. Desarrollar el acta de constitución del proyecto

\begin{tabular}{|c|c|c|c|c|}
\hline $\begin{array}{c}\text { ID } \\
\text { Actividad }\end{array}$ & Actividad & Responsable & $\begin{array}{c}\text { ID } \\
\text { Formato }\end{array}$ & $\begin{array}{l}\text { Nombre } \\
\text { formato }\end{array}$ \\
\hline PI01-1 & $\begin{array}{l}\text { Asigne al director del } \\
\text { proyecto, así como su } \\
\text { responsabilidad y autoridad }\end{array}$ & \multirow{10}{*}{$\begin{array}{l}\text { Dirección } \\
\text { de proyectos }\end{array}$} & \multirow{10}{*}{ Fl01 } & \multirow{10}{*}{$\begin{array}{l}\text { Acta de } \\
\text { constitución } \\
\text { del proyecto }\end{array}$} \\
\hline PI01-2 & $\begin{array}{l}\text { Realice una descripción } \\
\text { del proyecto (problema/ } \\
\text { oportunidad, justificación, } \\
\text { propósito, metas / objetivos, } \\
\text { entregables esperados, } \\
\text { código del proyecto) }\end{array}$ & & & \\
\hline PI01-3 & $\begin{array}{l}\text { Defina cuáles son los criterios } \\
\text { de éxito del proyecto }\end{array}$ & & & \\
\hline PI01-4 & $\begin{array}{l}\text { Realice una descripción de } \\
\text { los hitos clave del proyecto }\end{array}$ & & & \\
\hline PI01-5 & $\begin{array}{l}\text { Conozca las restricciones } \\
\text { tiempo, presupuesto } \\
\text { y recursos }\end{array}$ & & & \\
\hline PI01-6 & $\begin{array}{l}\text { Conozca los requisitos } \\
\text { de alcance y calidad }\end{array}$ & & & \\
\hline PI01-7 & $\begin{array}{l}\text { Identifique supuestos } \\
\text { y riesgos }\end{array}$ & & & \\
\hline PI01-8 & $\begin{array}{l}\text { Describa cuáles son los } \\
\text { beneficios del proyecto }\end{array}$ & & & \\
\hline PI01-9 & $\begin{array}{l}\text { Describa cuáles son las } \\
\text { personas interesadas que } \\
\text { puedan ser afectadas de } \\
\text { manera positiva o negativa } \\
\text { por el proyecto }\end{array}$ & & & \\
\hline PI01-10 & $\begin{array}{l}\text { Busque la autorización } \\
\text { del patrocinador para la } \\
\text { aceptación del acta de } \\
\text { constitución del proyecto }\end{array}$ & & & \\
\hline
\end{tabular}

Fuente: elaboración propia.

Los procedimientos contienen diferentes formatos, cada uno, ajustado al respectivo proceso. Los formatos tienen cinco secciones:

- Nombre y código del proceso: sección en la que se especifica el código del proceso, formato y nombre del proceso. Varía de acuerdo con su grupo de procesos.

- Encabezado: contiene datos de entrada como la titulación del proyecto, director del proyecto y fecha en la cual se está utilizando el formato. 
- Cuerpo del formato: es el contenido del formato e información propia de cada proceso.

- Pie de página: son datos informativos como código, nombre y versión del formato (Universidad Politécnica, 2017).

- Color del grupo de proceso: distintivo visual de los grupos de procesos de la metodología.

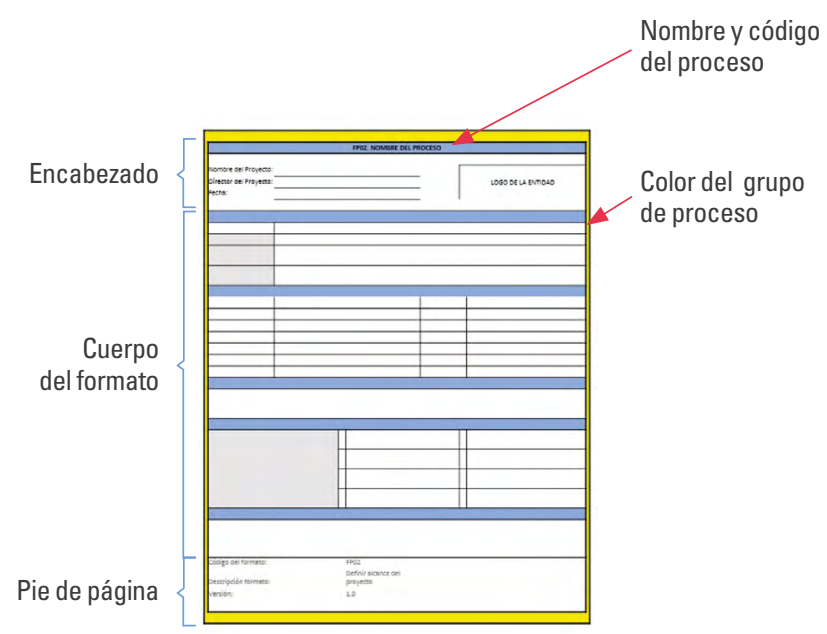

Figura 9. Distribución formatos

Fuente: elaboración propia.

\section{Validación de la metodología}

El proceso de validación de esta metodología se desarrolló con el juicio de expertos. En este caso, se tomó en cuenta el análisis y el criterio de diez expertos seleccionados del sector aeroespacial en Colombia y, del área de gerencia de proyectos en el ámbito nacional e internacional (véase apéndices, al final del documento).

A cada experto se le entregó la metodología y una encuesta, estas fueron leídas y analizadas durante 20 días, posteriormente, cada experto diligenció la encuesta según su criterio, la cual contiene la evaluación de la metodología y, por último, entregaron la encuesta diligenciada. Las observaciones y sugerencias recibidas fueron de apoyo para el proceso de acciones, apreciaciones, ajustes y observaciones del avance de la metodología (véase apéndices, al final del documento).

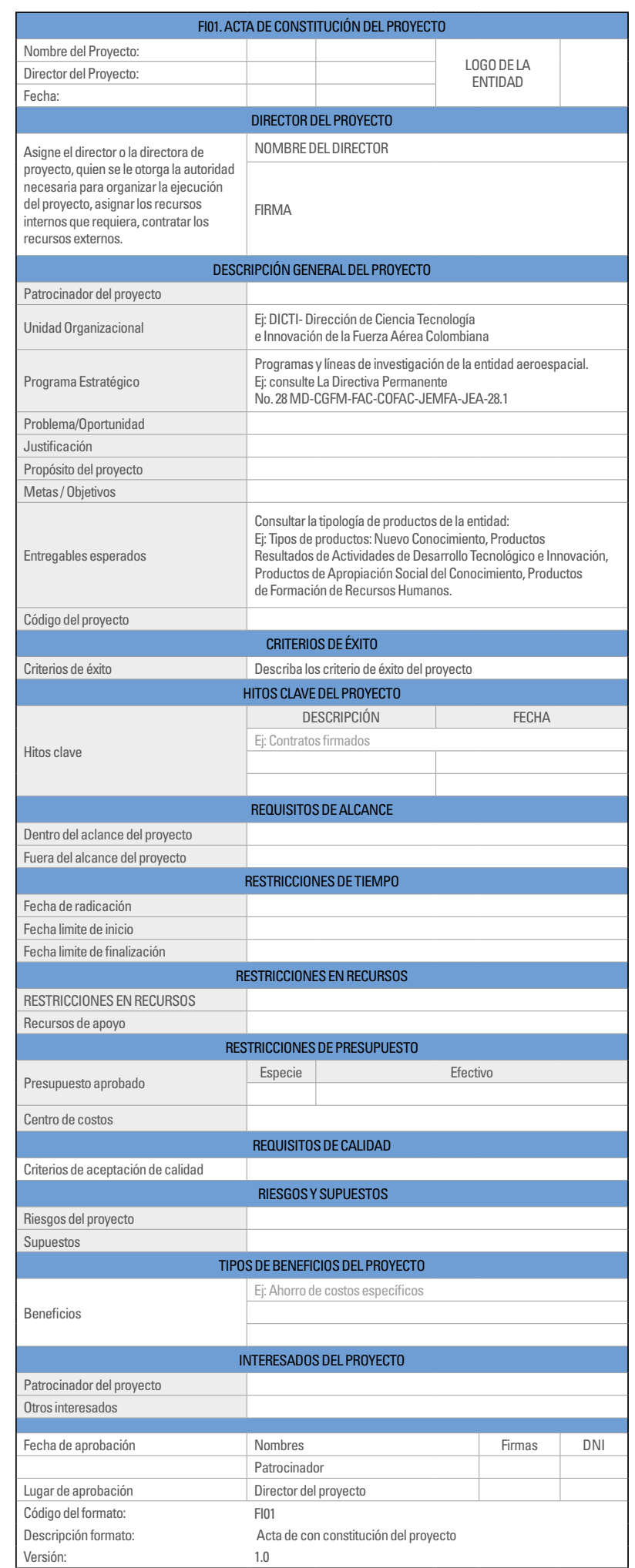

Figura 10. Ejemplo del formato del procedimiento “Desarrollar el acta de constitución del proyecto. Grupo de procesos de inicio"

Fuente: elaboración propia. 


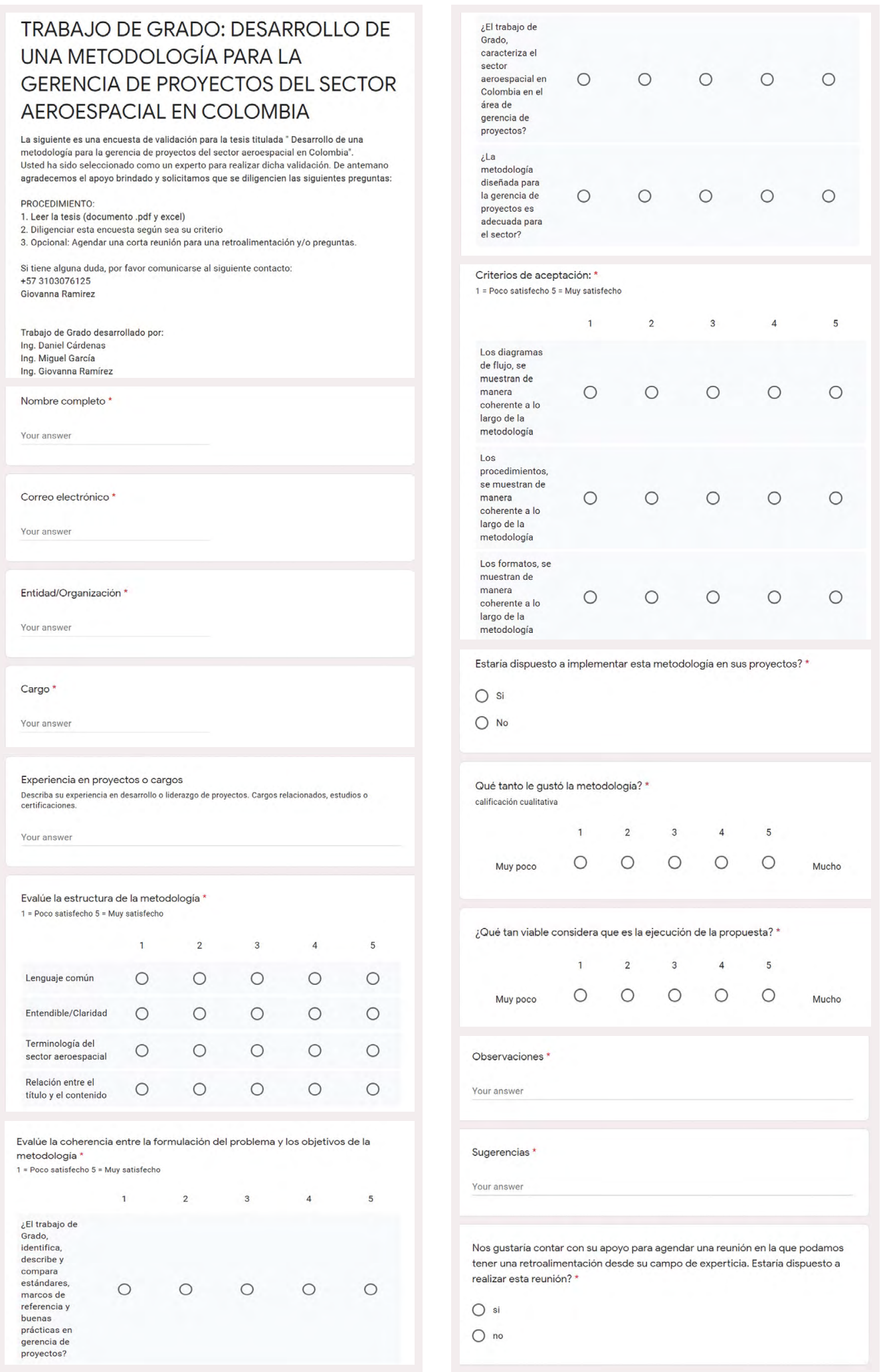

Figura 11. Encuesta juicio de expertos

Fuente: elaboración propia. 
Los criterios de evaluación de la encuesta se seleccionaron con base en la información y retroalimentación obtenida en reuniones con los expertos, verificación de antecedentes y sugerencias de la ingeniera Erika Sofía Olaya Escobar, docente de la Escuela Colombiana de Ingeniería, experta en el ámbito de formulación, y evaluación de proyectos.
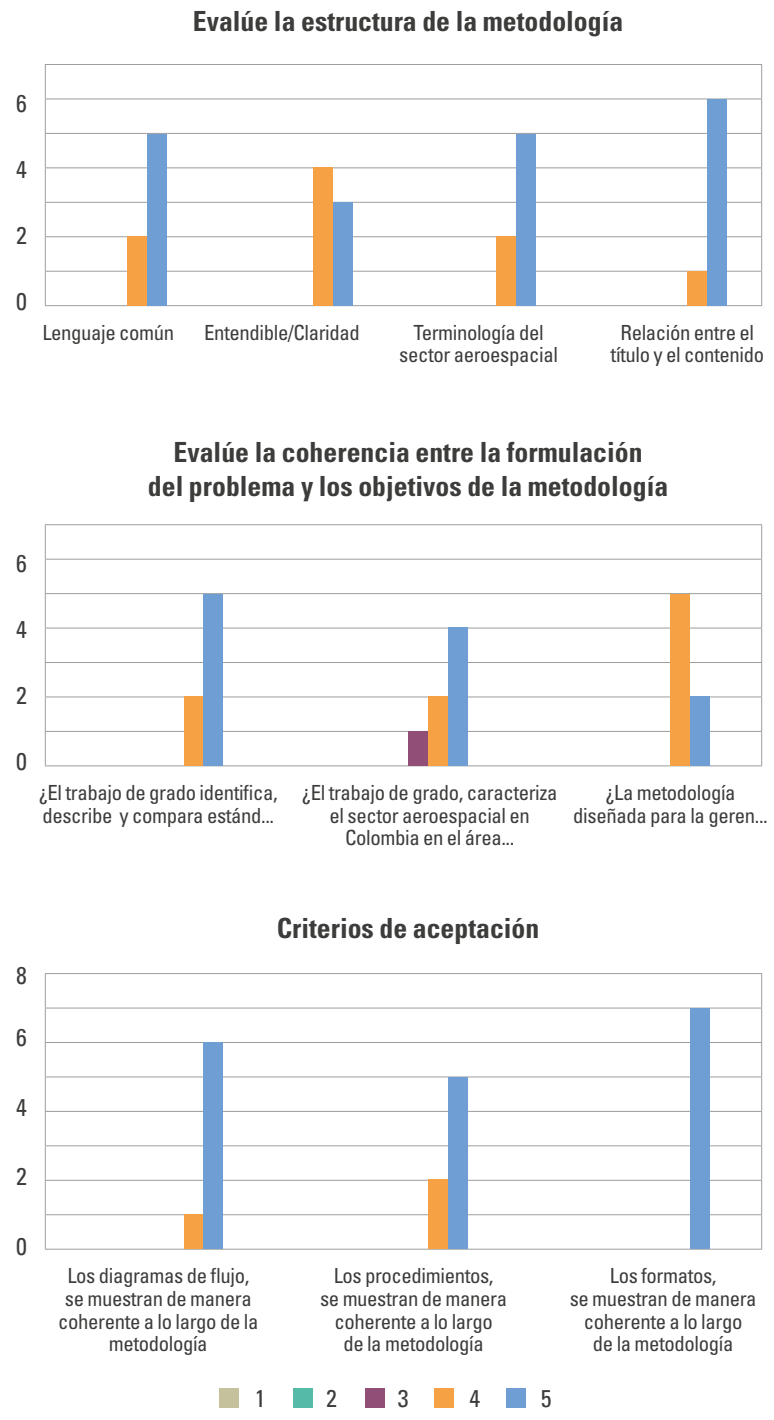

Figura 12. Análisis de encuestas

Fuente: elaboración propia.

Dentro de las observaciones y sugerencias recopiladas de los expertos a través de la encuesta, se presentaron cambios de fondo, estructura y contenido. Estos se incorporaron a la investigación y se realizó la restructuración pertinente, para que la metodología desarrollada fuera más incluyente de acuerdo con la retroalimentación de los profesionales del sector aeroespacial en Colombia.

\section{Conclusiones}

La industria aeronáutica internacional ha venido en un crecimiento acelerado a lo largo de los años. En el caso de Colombia, el crecimiento del sector aeroespacial se ha visto beneficiado por organismos como la Fuerza Aérea de Colombia y la Aeronáutica Civil.

Estas organizaciones son las principales entidades públicas que desempeñan un papel dentro de la industria aeroespacial colombiana, en la que existe un fuerte componente de seguridad nacional que condiciona la participación del Estado, lo que implica que la inversión, modernización y actividades de la industria aeroespacial, se fundamenten desde una visión de la gestión pública.

Partiendo del análisis de resultados de la investigación, se evidencia que la metodología aplicada para la gestión de proyectos en la división aeroespacial, recopila 11 grupos con 56 procesos de gerencia, dentro de los cuales se identificaron 25 procesos en común con los estándares internacionales tomados como referencia. Además, se adicionaron 11 procesos particulares que complementan la metodología.

Con respecto a la Fuerza Aérea Colombiana, se identificó que la entidad no lleva los procesos de definición y control del alcance, planificación y gestión de la calidad e implementación y monitoreo de los riesgos.

En el caso de la Aeronáutica Civil se evidenció la carencia de supervisión de procesos, como por ejemplo, la realización del monitoreo integral de los cambios, creación de la EDT, control del alcance, gestión y participación de los interesados.

Por ello, se concluye que ambas entidades no desarrollan los procesos de control, alcance y monitoreo de las comunicaciones. Motivo por el cual, el desarrollo de la metodología incluye los procesos faltantes de 
cada organización, incluyendo los respectivos formatos que servirán de apoyo a la gestión interna de los proyectos y a la articulación puesta en marcha de procesos de gerencia entre organizaciones del sector a la hora de presentar proyectos en conjunto.

Ahora bien, con respecto a los expertos seleccionados para la validación de la metodología, se obtuvieron resultados satisfactorios en la evaluación de parámetros tales como la estructura, la coherencia y los criterios de evaluación de la metodología.

Finalmente, la metodología se convierte en una herramienta para el sector aeroespacial colombiano que puede mejorar la gestión y la articulación de proyectos de las entidades, aunque esto implica un trabajo futuro que complemente la metodología con los procesos faltantes, técnicas y herramientas vigentes, nacionales e internacionales en gerencia integral de proyectos.

De manera opcional, se puede realizar un amplio estudio del sector aeroespacial, teniendo en cuenta a los actores del tripe hélice que se determinan en la academia, la industria y el Estado. Aspecto que se establece con el objetivo de hacer partícipes a más entes del sector y aplicar la metodología desarrollada en proyectos, en cooperación con la industria, el Gobierno, la academia y, alianzas nacientes que involucren a la sociedad.

Declaración de conflicto de interés: Los autores no manifiestan conflictos de interés institucionales ni personales.

\section{Referencias}

Aerocivil. (2016). Aviación para la paz. Aeronáutica Civil. https://www.aerocivil.gov.co/atencion/estadisticas-de-las-actividades-aeronauticas/Estudios $\% 20 y \% 20$ publicaciones/AVIACI\%C3\%93N\%20PARA\%20LA\%20 PAZ\%20DIC\%202016.pdf

Aerocivil. (2019). Plan estratégico aeronáutico 2030. Aeronáutica Civil. https://www.aerocivil.gov.co/aerocivil/ II-FORO2030/Documents/Resumen\%20Ejecutivo\%20 Plan\%20Estrat\%C3\%A9gico\%20Aeron\%C3\%A1utico \%202030.pdf
Aerocivil. (2020). Autoridad de la Aviación Civil. Aeronáutica Civil. https://www.aerocivil.gov.co/autoridad-de-laaviacion-civil

Aerocivil. (2020, 28 de diciembre). Planes en construcción. Aeronáutica Civil. https://www.aerocivil.gov.co/atencion/ participacion/planes-en-construccion

Barne, D., \& Wadhwa, D. (2018, 21 de diciembre). Resumen anual: el año 2018 en 14 gráficos. Banco Mundial. https:// www.bancomundial.org/es/news/feature/2018/12/21/ year-in-review-2018-in-14-charts

Bello, A. (2017). Análisis de clústeres aeronáuticos referentes para el desarrollo del clúster aeroespacial colombiano. Ciencia y Poder Aéreo, 12(1), 36-58. https://doi. org/10.18667/cienciaypoderaereo.560

Cardoza, A., Guerrero, D., \& Ríos, I. (2011). Comparación de cuatro sistemas de certificación del Ámbito de la dirección de proyectos. XV Congreso Internacional de Ingeniería de Proyectos. http://oa.upm.es/12809/1/INVE_ MEM_2011_107522.pdf

CIAC. (2020, 24 de septiembre). La industria 4.0 en el desarrollo del sector aeroespacial colombiano. CIAC. https://www. ciac.gov.co/blog/articulo/?id=262

Conpes. (2020). Política de desarrollo espacial: condiciones habilitantes para el impulso de la competitividad nacional. Documento Conpes 3983. Consejo Nacional de Política Económica Y Social; República de Colombia; Departamento nacional de planeación. https://colaboracion. dnp.gov.co/CDT/Conpes/Econ\%C3\%B3micos/3983.pdf

Córdoba, G. (2019). Los nuevos retos, roles y responsabilidades de la Fuerza Aérea Colombiana en el marco de la implementación de los Acuerdos de Paz [tesis de Maestría, Pontificia Universidad Javeriana]. https://repository.ja veriana.edu.co/handle/10554/45094

Delgado-Gómez, P. (2018, 2 de septiembre). En Colombia hay industria aeronáutica. El Espectador. https://www. elespectador.com/economia/en-colombia-hay-industriaaeronautica-article- 809827/

FAC. (2020). Plan de acción FAC 2019. Fuerza Aérea Colombiana. https://d2r89ls1uje5rg.cloudfront.net/sites/default/fi les/plan_de_accion_fuerza_aerea_2019_0.pdf

Función Pública. (2014). Manual Técnico del Modelo Estándar de Control Interno para el Estado Colombiano MECI 2014. Departamento Administrativo de la Función Pública. https://www.funcionpublica.gov.co/documents/ 418537/506911/Manual+T\%C3\%A9cnico+del+Modelo+ Est\%C3\%A1ndar+de+Control+Interno+para+el+Estado+Colombiano+MECl+2014/065a3838-cc9f-4eeb-a308 $-21 b 2 a 7 a 040 b d$ 
Granada, J., Rivera, S., Saavedra, G., Ramos, G., Segura, J., Espinel, F., Ballesteros, M., Vallejo, M., \& Rodríguez, H. (2017). Plan Estratégico de la Industrial Colombiana Aeroespacial (Peica). Acopaer. https://acopaer.org/docu mentos/

International Project Management Association (IPMA). (2016, 12 de diciembre). Projects and project management in China. International Project Management Association. https://www.ipma.world/projects-andproject-management-in-china/

ISO. (2012). ISO 21500 Directrices para la Dirección y Gestión de Proyectos. https://www.isotools.org/2017/07/11/ norma-iso-21500-guia-gestion-proyectos/

Martínez, W. E. L., \& Morante F. (2018). Análisis de modelos de clústeres aeroespaciales más representativos a nivel mundial y su incidencia para el desarrollo del Clúster Aeroespacial del Valle del Cauca. Ciencia y poder aéreo, 13(1), 114-122.

Monsalve, J. S. (2019). Aplicación de la guía PMBOK 6 ed. en la planificación de la construcción de viviendas tipo (VIS) en el municipio de valdivia (Antioquia), con materiales ecológicos WPC. Universidad Católica de Colombia. https:// repository.ucatolica.edu.co/bitstream/10983/23413/1/. Proyecto\%20de\%20Grado\%20-\%20Viviendas\%20VIS con\%20material\%20WPC\%20-\%2028-05-2019.pdf

Murray-Webster, R., \& Dalcher, D. (Eds.) (2019). APM Body of Knowledge ( $7^{\text {th }} \mathrm{Ed}$.). Association for Project Management. https://www.apm.org.uk/book-shop/apm-bodyof-knowledge-7th-edition

PMBoK. (2021, 12 de mayo). Guía de los Fundamentos para la Dirección de Proyectos (Guía del PMBOK ${ }^{\circledR}$ ). https://www. pmi.org/-/media/pmi/documents/public/pdf/pmbokstandards/pmbok-guide-6th-errata.pdf?v=66712958a626-47f6-b285-b3f24cf29dc4\&sc_lang_temp=es-ES

Project Management Association of Japan. (2016). P2M. Program \& Project Management for Enterprise Innovation. PMAJ. https://www.pmaj.or.jp/ENG/p2m/p2m_guide/ p2m_guide.html

Project Management Institute. (2017). Business Analysis for Practitioners: A Practice Guide. Project Management Institute.

Suárez, M. (2020). Análisis de las estrategias e innovación del desarrollo del clúster aeroespacial en Colombia. Universidad Militar.

\section{Apéndice A}

Árbol problema del sector aeroespacial, con sus respectivas causas y efectos, según la problemática escogida.

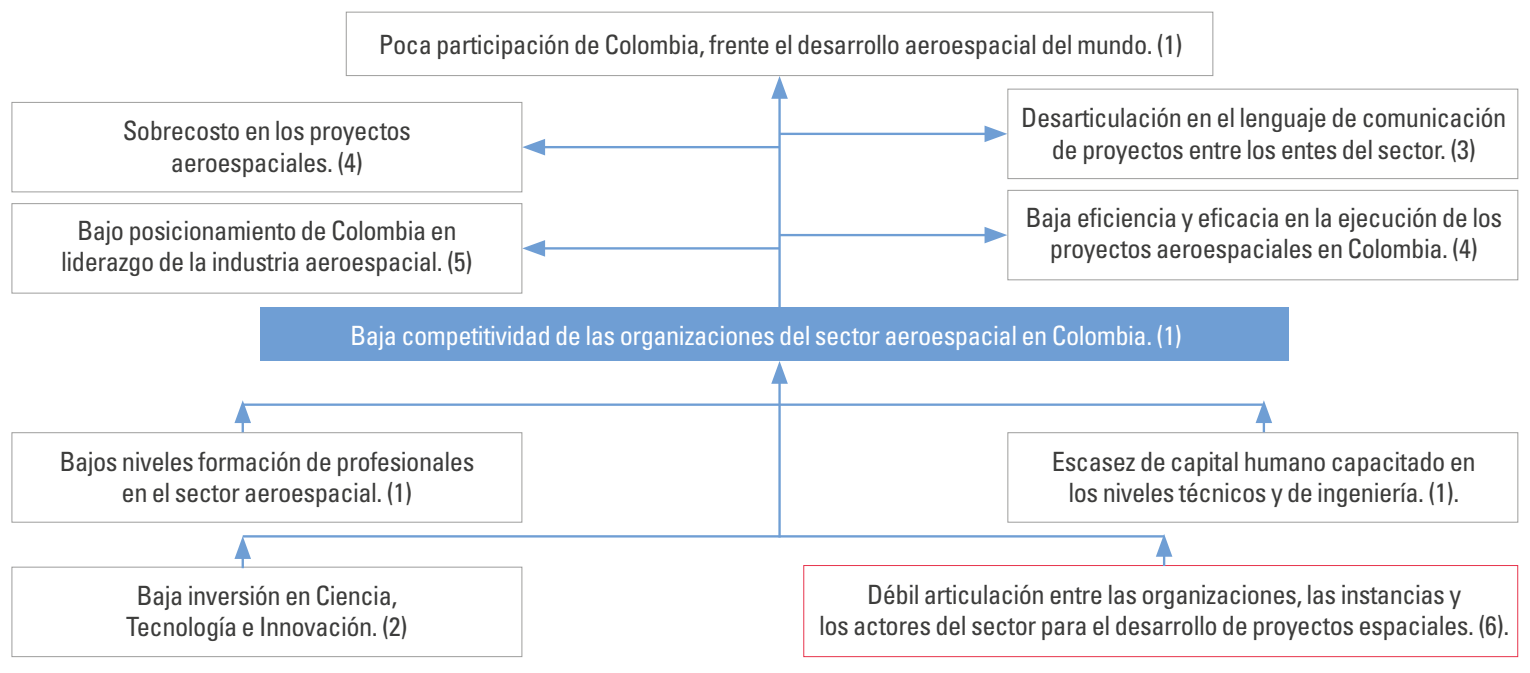

Figura A1. Árbol problema del sector aeroespacial en Colombia

Fuente: Granada et al. (2017), Barne (2018), Córdoba (2019), Spectrum (2018), Cárdenas (2013) y Guaque (2015). 


\section{Apéndice B}

\section{Comparación de los diferentes procesos que maneja cada uno de los estándares.}

Tabla B1

Comparación de estándares

\begin{tabular}{|c|c|c|c|c|c|c|}
\hline \multicolumn{2}{|c|}{ PROCESOS } & \multirow{2}{*}{$\begin{array}{c}\text { PMBOK } \\
X\end{array}$} & \multirow[t]{2}{*}{ APMBOK } & \multirow{2}{*}{$\begin{array}{c}\text { ICB } \\
X\end{array}$} & \multirow{2}{*}{$\begin{array}{c}\text { ISO 21500:2012 } \\
X\end{array}$} & \multirow[t]{2}{*}{ P2M } \\
\hline Gestión Integración & Desarrollar el Acta de Constitución del Proyecto & & & & & \\
\hline & Desarrollar el Plan para la Dirección del Proyecto & $\mathrm{X}$ & $\mathrm{X}$ & $\mathrm{x}$ & $\mathrm{X}$ & \\
\hline & Definir el Ciclo de Vida del Proyecto & & & & & $\mathrm{X}$ \\
\hline & Dirigir y Gestionar el Trabajo del Proyecto & $\mathrm{X}$ & $\mathrm{X}$ & $\mathrm{X}$ & $\mathrm{X}$ & $\mathrm{X}$ \\
\hline & Gestionar el Conocimiento del Proyecto & $\mathrm{X}$ & $\mathrm{X}$ & $X$ & $X$ & $\mathrm{X}$ \\
\hline & Monitorear y Controlar el Trabajo del Proyecto & $\mathrm{X}$ & $\mathrm{X}$ & $\mathrm{X}$ & $\mathrm{X}$ & \\
\hline & Realizar el Control Integrado de Cambios & $\mathrm{X}$ & $\mathrm{X}$ & $\mathrm{X}$ & $\mathrm{X}$ & $\mathrm{X}$ \\
\hline & Cerrar el Proyecto o Fase & $\mathrm{X}$ & & $\mathrm{X}$ & $\mathrm{X}$ & \\
\hline \multirow{5}{*}{ Gestión Alcance } & Recopilar Requisitos & $\mathrm{X}$ & $\mathrm{X}$ & & & $\mathrm{X}$ \\
\hline & Definir el Alcance & $\mathrm{x}$ & $\mathrm{X}$ & $\mathrm{x}$ & $x$ & $\mathrm{x}$ \\
\hline & Crear la EDT/WBS & $\mathrm{X}$ & $\mathrm{X}$ & $\mathrm{X}$ & $\mathrm{X}$ & $\mathrm{X}$ \\
\hline & Validar el Alcance & $\mathrm{X}$ & $X$ & & & \\
\hline & Controlar el Alcance & $\mathrm{X}$ & $\mathrm{X}$ & $\mathrm{X}$ & $\mathrm{X}$ & $X$ \\
\hline \multirow[t]{4}{*}{ Gestión del Cronograma } & Planificar la Gestión del Cronograma & $\mathrm{X}$ & $\mathrm{X}$ & & & \\
\hline & Definir las Actividades & $\mathrm{X}$ & $\mathrm{X}$ & $\mathrm{X}$ & $x$ & \\
\hline & Secuenciar las Actividades & $\mathrm{x}$ & $\mathrm{X}$ & $\mathrm{X}$ & $\mathrm{X}$ & \\
\hline & Controlar el Cronograma & $\mathrm{X}$ & $\mathrm{X}$ & $\mathrm{X}$ & $\mathrm{X}$ & $\mathrm{X}$ \\
\hline \multirow[t]{6}{*}{ Gestión de Costos } & Asegurar el compromiso de la organización con los fondos & & $\mathrm{X}$ & & & \\
\hline & Planificar la Gestión de los Costos & $\mathrm{X}$ & $\mathrm{X}$ & & & $\mathrm{X}$ \\
\hline & Estimar los Costos & $\mathrm{x}$ & $\mathrm{X}$ & $\mathrm{X}$ & $\mathrm{X}$ & $\mathrm{X}$ \\
\hline & Evaluar el flujo de caja en el contexto del proyecto & & $\mathrm{X}$ & & & \\
\hline & Determinar el presupuesto & $\mathrm{X}$ & & $\mathrm{X}$ & $\mathrm{X}$ & \\
\hline & Controlar los Costos & $\mathrm{X}$ & $X$ & $\mathrm{X}$ & $\mathrm{X}$ & $\mathrm{X}$ \\
\hline \multirow[t]{3}{*}{ Gestión de la Calidad } & Planificar la Gestión de la Calidad & $\mathrm{X}$ & $\mathrm{X}$ & $\mathrm{X}$ & $\mathrm{X}$ & $\mathrm{X}$ \\
\hline & Gestionar la Calidad & $\mathrm{X}$ & $\mathrm{X}$ & $\mathrm{X}$ & $\mathrm{X}$ & $\mathrm{X}$ \\
\hline & Controlar la Calidad & $\mathrm{X}$ & $\mathrm{X}$ & $x$ & $\mathrm{X}$ & \\
\hline \multirow[t]{7}{*}{ Gestión de los Recursos } & Planificar la Gestión de Recursos & $\mathrm{X}$ & $\mathrm{X}$ & $\mathrm{X}$ & $\mathrm{X}$ & $\mathrm{X}$ \\
\hline & Estimar los Recursos de las Actividades & $\mathrm{x}$ & $\mathrm{X}$ & $\mathrm{X}$ & $\mathrm{X}$ & $\mathrm{X}$ \\
\hline & Definir la Organización del Proyecto & & $\mathrm{X}$ & $\mathrm{X}$ & $\mathrm{X}$ & $\mathrm{X}$ \\
\hline & Adquirir Recursos & $\mathrm{X}$ & $\mathrm{X}$ & & & $\mathrm{X}$ \\
\hline & Desarrollar el Equipo & $\mathrm{x}$ & & $\mathrm{X}$ & $\mathrm{x}$ & $\mathrm{X}$ \\
\hline & Dirigir al Equipo & $\mathrm{X}$ & $x$ & $\mathrm{X}$ & $\mathrm{X}$ & $x$ \\
\hline & Controlar los Recursos & $X$ & $X$ & $\mathrm{X}$ & $X$ & $\mathrm{X}$ \\
\hline $\begin{array}{l}\text { Gestión de las } \\
\text { Comunicaciones }\end{array}$ & Monitorear las Comunicaciones & $\mathrm{X}$ & $\mathrm{X}$ & $\mathrm{X}$ & $\mathrm{X}$ & $\mathrm{X}$ \\
\hline \multirow[t]{7}{*}{ Gestión de los Riesgos } & Planificar la Gestión de los Riesgos & $\mathrm{X}$ & $\mathrm{X}$ & & & $\mathrm{X}$ \\
\hline & Identificar los Riesgos & $\mathrm{X}$ & $\mathrm{X}$ & $\mathrm{X}$ & $\mathrm{X}$ & $\mathrm{X}$ \\
\hline & Realizar el Análisis Cualitativo de Riesgos & $\mathrm{X}$ & $\mathrm{X}$ & $\mathrm{X}$ & $\mathrm{X}$ & \\
\hline & Realizar el Análisis Cuantitativo de Riesgos & $\mathrm{X}$ & $\mathrm{X}$ & & & $\mathrm{X}$ \\
\hline & Planificar la Respuesta a los Riesgos & $\mathrm{X}$ & $\mathrm{X}$ & & & $\mathrm{X}$ \\
\hline & Implementar la Respuesta a los Riesgos & $\mathrm{X}$ & $\mathrm{X}$ & $X$ & $X$ & $\mathrm{X}$ \\
\hline & Monitorear los Riesgos & $\mathrm{X}$ & $\mathrm{X}$ & $\mathrm{X}$ & $X$ & $\mathrm{X}$ \\
\hline \multirow{4}{*}{$\begin{array}{l}\text { Gestión de las } \\
\text { Adquisiciones }\end{array}$} & Planificar la Gestión de las Adquisiciones & $\mathrm{X}$ & $\mathrm{X}$ & $\mathrm{X}$ & $\mathrm{X}$ & $\mathrm{X}$ \\
\hline & Seleccione proveedores & & $\mathrm{X}$ & $\mathrm{X}$ & $\mathrm{X}$ & \\
\hline & Efectuar las Adquisiciones & $\mathrm{X}$ & $\mathrm{X}$ & & & $\mathrm{X}$ \\
\hline & Controlar las Adquisiciones & $\mathrm{X}$ & $\mathrm{X}$ & $\mathrm{X}$ & $\mathrm{X}$ & $\mathrm{X}$ \\
\hline \multirow{4}{*}{$\begin{array}{l}\text { Gestión de los } \\
\text { Interesados }\end{array}$} & Identificar a los interesados & $\mathrm{X}$ & $\mathrm{X}$ & $\mathrm{X}$ & $\mathrm{X}$ & \\
\hline & Planificar el Involucramiento de los Interesados & $\mathrm{X}$ & $\mathrm{X}$ & & & $\mathrm{x}$ \\
\hline & Gestionar la Participación de los Interesados & $\mathrm{X}$ & $\mathrm{X}$ & $\mathrm{X}$ & $\mathrm{X}$ & $\mathrm{X}$ \\
\hline & Monitorear el Involucramiento de los Interesados & $\mathrm{X}$ & & & & $\mathrm{X}$ \\
\hline \multirow[t]{2}{*}{ Gestión del Valor Ganado } & Identificar y Cuantificar el Valor del Proyecto & & $\mathrm{X}$ & & & $\mathrm{X}$ \\
\hline & $\begin{array}{l}\text { Identificar oportunidades potenciales de creación de valor } \\
\text { y generar recursos de creación de valor relevantes }\end{array}$ & & & & & $\mathrm{x}$ \\
\hline Gestión de la Información & Gestionar la información del Proyecto & & $\mathrm{X}$ & & & \\
\hline
\end{tabular}

Fuente: elaboración propia. 


\section{Apéndice C}

Diagramas de flujo adicionales presentes en la metodología.

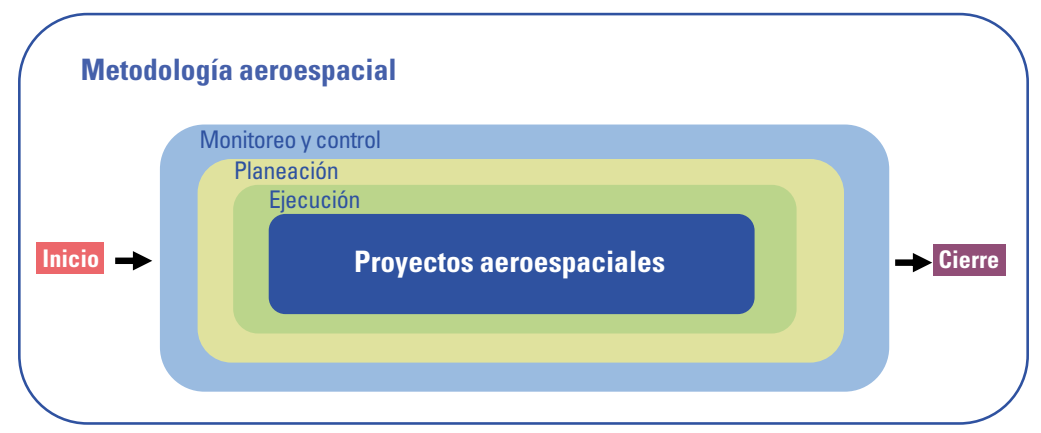

Figura C1. Diagrama de flujo general

Fuente: elaboración propia.

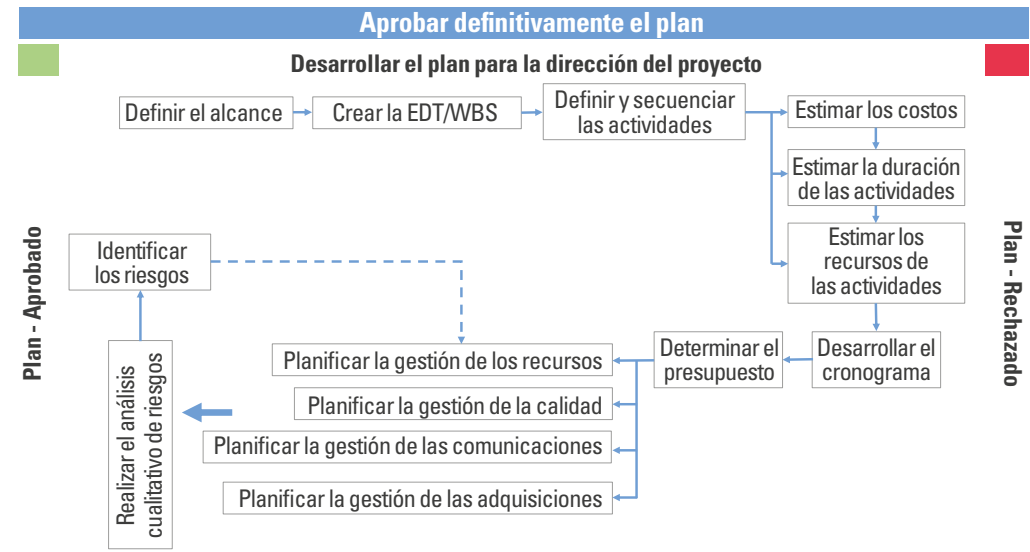

Figura C2. Diagrama de flujo planeación

Fuente: elaboración propia.

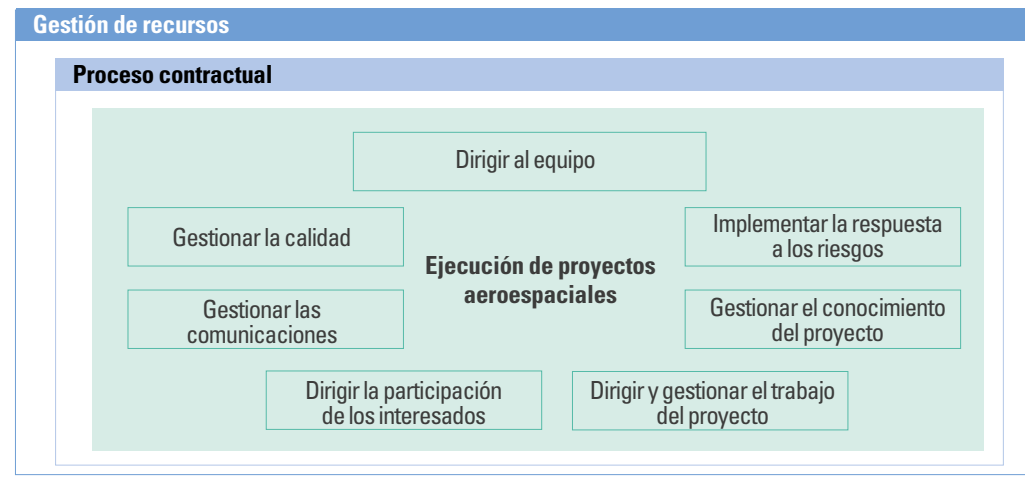

Figura C3. Diagrama de flujo ejecución

Fuente: elaboración propia. 
Monitorear y controlar el trabajo del proyecto

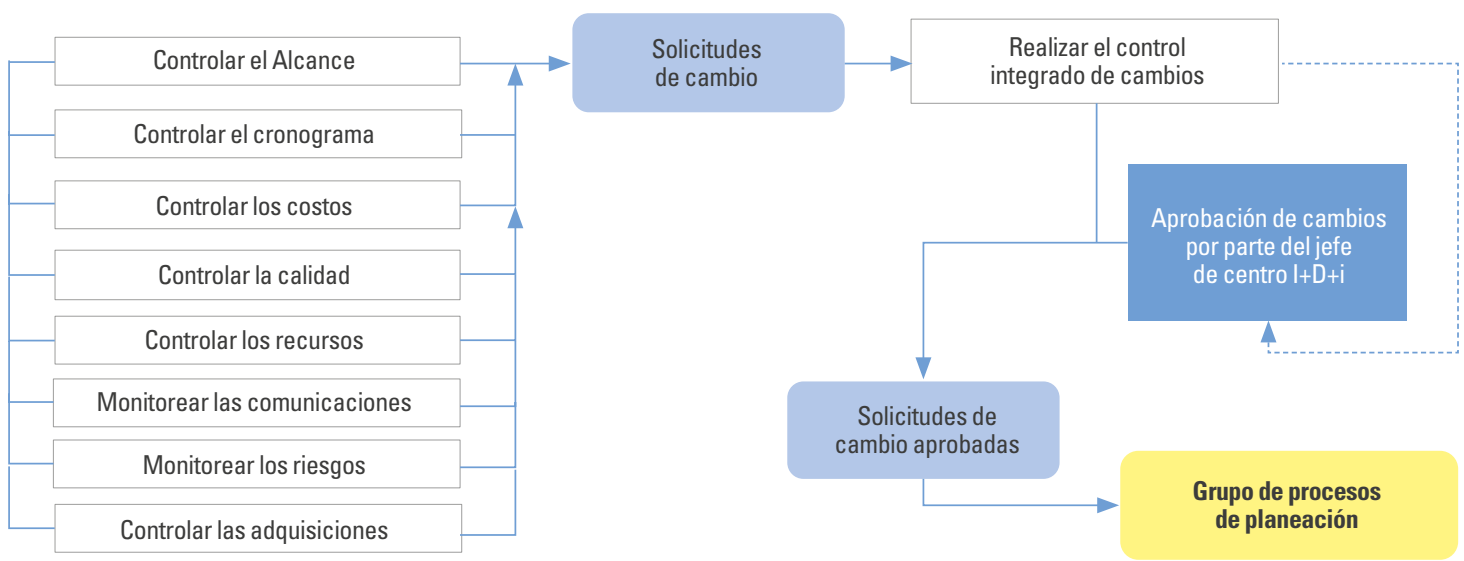

Figura C4. Diagrama de flujo monitoreo y control

Fuente: elaboración propia.

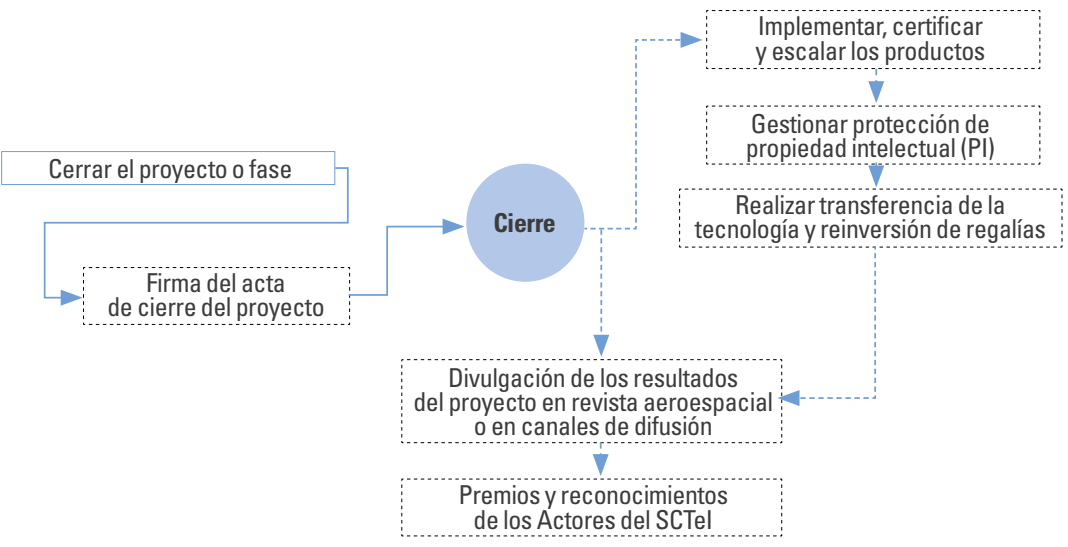

Figura C5. Diagrama de flujo cierre

Fuente: elaboración propia. 